\title{
New Napyradiomycin Analogues from Streptomyces sp. Strain CA-271078
}

\author{
Daniel Carretero-Molina ${ }^{1,2}$ (), Francisco Javier Ortiz-López ${ }^{1, *} \mathbb{C}$, Jesús Martín ${ }^{1}$, \\ Daniel Oves-Costales ${ }^{1}$, Caridad Díaz ${ }^{1}$, Mercedes de la Cruz ${ }^{1} \mathbb{D}$, Bastien Cautain ${ }^{1}$, \\ Francisca Vicente ${ }^{1}$, Olga Genilloud ${ }^{1}\left[\right.$ and Fernando Reyes ${ }^{1, *(1)}$
}

1 Fundación MEDINA, Centro de Excelencia en Investigación de Medicamentos Innovadores en Andalucía, Avda. del Conocimiento 34, 18016 Armilla (Granada), Spain; daniel.carretero@medinaandalucia.es (D.C.-M.); jesus.martin@medinaandalucia.es (J.M.); daniel.oves@medinaandalucia.es (D.O.-C.); caridad.diaz@medinaandalucia.es (C.D.); mercedes.delacruz@medinaandalucia.es (M.d.l.C.); bastien.cautain@medinaandalucia.es (B.C.); francisca.vicente@medinaandalucia.es (F.V.); olga.genilloud@medinaandalucia.es (O.G.)

2 Doctoral Programme in Pharmacy (B15.56.1), Doctoral School in Health Sciences, University of Granada, 52005 Granada, Spain

* Correspondence: javier.ortiz@medinaandalucia.es (F.J.O.-L.); fernando.reyes@medinaandalucia.es (F.R.); Tel.: +34-958-993-965 (F.J.O.-L. \& F.R.)

Received: 10 December 2019; Accepted: 25 December 2019; Published: 26 December 2019

\begin{abstract}
As part of our continuing efforts to discover new bioactive compounds from microbial sources, a reinvestigation of extracts of scaled-up cultures of the marine-derived Streptomyces sp. strain CA-271078 resulted in the isolation and structural elucidation of four new napyradiomycins $(\mathbf{1}-\mathbf{3}, \mathbf{5})$. The known napyradiomycin SC (4), whose structural details had not been previously described in detail, and another ten related known compounds (6-15). The structures of the new napyradiomycins were characterized by HRMS and 1D- and 2D-NMR spectroscopies and their relative configurations were established through a combination of molecular modelling with $n O e$ and coupling constants NMR analysis. The absolute configuration of each compound is also proposed based on biosynthetic arguments and the comparison of specific rotation data with those of related compounds. Among the new compounds, $\mathbf{1}$ was determined to be the first non-halogenated member of napyradiomycin A series containing a functionalized prenyl side chain, while 2-4 harbor in their structures the characteristic chloro-cyclohexane ring of the napyradiomycin B series. Remarkably, compound 5 displays an unprecedented 14-membered cyclic ether ring between the prenyl side chain and the chromophore, thus representing the first member of a new class of napyradiomycins that we have designated as napyradiomycin D1. Anti-infective and cytotoxic properties for all isolated compounds were evaluated against a set of pathogenic microorganisms and the HepG2 cell line, respectively. Among the new compounds, napyradiomycin D1 exhibited significant growth-inhibitory activity against methicillin-resistant Staphylococcus aureus, Mycobacterium tuberculosis, and HepG2.
\end{abstract}

Keywords: napyradiomycins; marine actinomycetes; structural elucidation; antimicrobial activity; cytotoxicity

\section{Introduction}

The napyradiomycins are a large class of unique meroterpenoids with different halogenation patterns whose structures consist of a semi-naphthoquinone chromophore, a prenyl unit attached at C-4a that is cyclized to form a tetrahydropyran ring in most cases and a monoterpenoid subunit attached to C-10a [1-6]. Many of the structural variants within this family reside in this C-10a attached 
side chain. Hitherto, about 50 napyradiomycin derivatives (NPDs) have been discovered. They have been sorted into three different types according to their structural features: Type A (NPD-As) with a linear terpenoid side chain; Type B (NPD-Bs) where the side chain is cyclized to form a cyclohexane ring; and Type C (NPD-Cs), whose monoterpenoid subunit is cyclized between C7 and C10a of the naphthoquinone core to form a 14-membered ring [1-13]. Compounds belonging to this structural class display a wide range of biological activities, including cytotoxic and antibiotic properties, as well as ATPases inhibition or estrogen receptor antagonization [14-17]. Napyradiomycins were first isolated from the soil-derived bacterium Chainia rubra in Japan in 1986 (later transferred to the genus Streptomyces) $[1,18]$. As time passed, a series of congeners were isolated from different actinomycetes including marine-derived strains [3,9].

Multi-drug resistance is one of the emergent threats in the healthcare area due to the loss of effective activity of some drugs against multi-resistant bacteria [19]. The discovery and development of new and safer sources of antibiotics has therefore become an essential matter. Microorganisms from the marine environment are an important source of structurally diverse and biologically active secondary metabolites, as evidenced by the growing number of new marine natural products isolated yearly from different biological sources, but research into the pharmacology of marine organisms is limited and most of it remains unexplored [20,21].

MEDINA's collection of actinomycetes and filamentous fungi is one of the biggest microbial collections worldwide and contains about ten percent of marine actinomycetes isolated from sediments samples collected along the seafloor [22]. As part of our continuous efforts to discover new bioactive compounds from microbial sources, we initiated a more in-depth study of scaled-up cultures of Streptomyces sp. CA-271078, a marine-derived actinomycete strain producing MDN-0170 in whose extracts we had also observed the presence of minor structurally related napyradiomycin congeners by LC/MS analysis [23]. Herein, we report the isolation, structure elucidation, and biological activities of four new napyradiomycin congeners $(\mathbf{1}-3,5)$ together with the description of the spectroscopic features of the known napyradiomycin SC (4), all isolated from the ethyl acetate extract of a culture broth of this strain.

\section{Results}

\subsection{Isolation and Taxonomy of the Producing Microorganism}

The isolation and taxonomy of the producing strain, CA-271078, were reported previously based on nearly-complete $16 \mathrm{~S}$ rRNA gene sequences (1359 bp, 94.2\% coverage) [23]. The data obtained strongly indicated that strain CA-271078 is a member of the genus Streptomyces and showed the closest relatedness with Streptomyces aculeolatus NBRC 14824(T) (99.34\% similarity).

\subsection{Extraction, Dereplication, and Bioassay-Guided Isolation}

The producing strain CA-271078 was fermented at $28^{\circ} \mathrm{C}$ in $3 \mathrm{~L}$ of R358 medium for 6 days. Extraction with an equal volume of acetone and evaporation of the organic solvent after centrifugation and filtration to discard the mycelial debris afforded an acetone crude extract, which was subsequently subjected to liquid-liquid extraction with EtOAc $(3 \times 1 \mathrm{~L})$. Analysis of this extract by LC/HRMS revealed the presence of some compounds that were not included in our in-house microbial natural products library [24] nor in the Chapman and Hall Dictionary of Natural Products [25].

The extract was subsequently chromatographed on a reversed-phase $\mathrm{C} 18$ column using a gradient of acetonitrile in water to afford five fractions: A-E. LC-DAD-HRMS analysis allowed us to establish that all these fractions contained possible known and bioactive NPDs bearing chlorine (according to their isotopic pattern), such as napyradiomycin B6 [26] and 18-hydroxynapyradiomycin A1 [6]. Additionally, these fractions also contained minor amounts of related NPDs whose molecular formulae suggested their novelty as natural products since they were not found in the Dictionary of Natural Products [25]. Further chromatographic separation on semipreparative reversed phase HPLC using a 
gradient of $\mathrm{CH}_{3} \mathrm{CN} / \mathrm{H}_{2} \mathrm{O}$, allowed us to isolate fifteen compounds (Figure S43). Napyradiomycins A3 (1), B7a (2), B7b (3), and D1 (5) (Figure 1) were identified as new compounds based on ESI-TOF and NMR analyses. Additionally, we have also isolated napyradiomycin SC (4) [27] (Figure 1) and its hitherto undescribed spectroscopic features will be reported here. Finally, the spectroscopic data of the rest of the compounds isolated (6-15) were identical to those previously reported for MDN-0170 (6) [23], 3-chloro-6, 8-dihydroxy-8- $\alpha$-lapachone (7) [10], 3-chloro-6-hydroxy-8-methoxy- $\alpha$-lapachone (8) [6], napyradiomycin B6 (9) [26], 18-hydroxynapyradiomycin A1 (10) [6], napyradiomycin A2a (11) [6], napyradiomycin A2b (12) [6], napyradiomycin B4 (13) [8], napyradiomycin B2 (14) [18], and napyradiomycin B5 (15) [26] (Figure S43).<smiles>C=C(C)C(O)CC/C(C)=C/C[C@]12OC(C)(C)[C@@H](O)C=C1C(=O)c1c(O)cc(O)cc1C2=O</smiles>

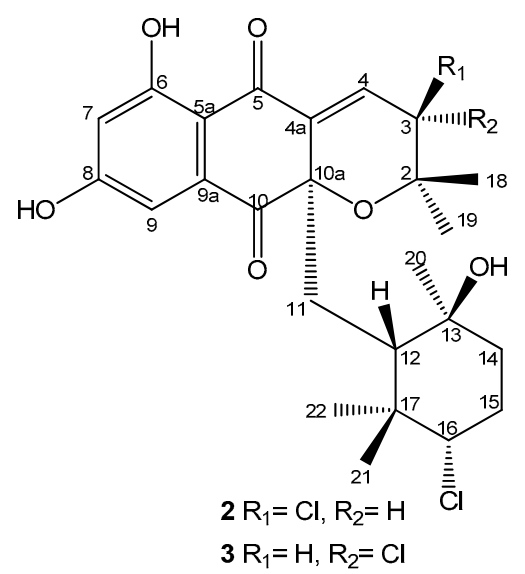

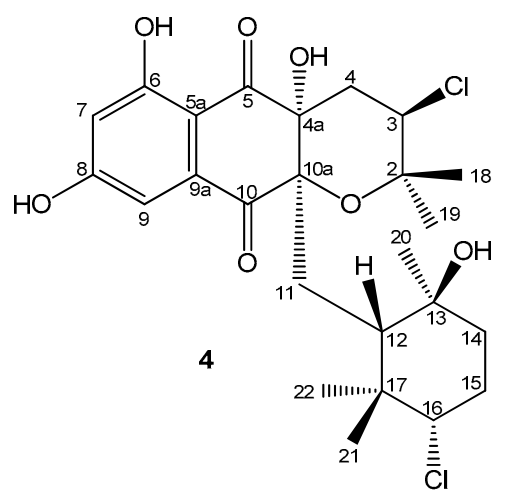<smiles>CC1=CCCC=CCC[C@@]2(Cl)C(=O)c3cc(O)cc(c3C2=O)O1</smiles>

Figure 1. Compounds 1-5 isolated from culture broths of Streptomyces sp. CA-271078.

\subsection{Structural Elucidation}

Compound 1 was obtained as a white powder and was assigned the molecular formula $\mathrm{C}_{25} \mathrm{H}_{30} \mathrm{O}_{7}$ (11 degrees of unsaturation) by analysis of the sodium adduct present in its ESI-TOF mass spectrum $\left(m / z 465.1878[\mathrm{M}+\mathrm{Na}]^{+}\right.$, calcd. for $\mathrm{C}_{25} \mathrm{H}_{30} \mathrm{NaO}_{7}{ }^{+}$, 465.1884) (Figure S1-A). The UV absorption pattern (Figure S1-B) with maxima at 258, 314, and $362 \mathrm{~nm}$ along with the IR spectrum of $\mathbf{1}$ (broad absorption bands at around $3294 \mathrm{~cm}^{-1}$ for multiple hydroxyl groups, and at $1701 \mathrm{~cm}^{-1}$ for a conjugated carbonyl functionality) suggested that this compound possessed the dihydronaphthoquinone moiety typically present in napyradiomycin metabolites.

The ${ }^{1} \mathrm{H}$ NMR spectrum of $\mathbf{1}$ (Table 1 and Figure S2) in DMSO- $d_{6}$ exhibited three deshielded signals attributable to two aromatic protons at $\delta_{\mathrm{H}} 6.57 \mathrm{ppm}(1 \mathrm{H}, \mathrm{d}, 2.1, \mathrm{H}-7)$ and $6.84 \mathrm{ppm}(1 \mathrm{H}, \mathrm{d}, 2.1, \mathrm{H}-9)$, and one downflield olefinic proton signal at $\delta_{\mathrm{H}} 6.89 \mathrm{ppm}(1 \mathrm{H}, \mathrm{d}, 6.4, \mathrm{H}-4)$. This suggested the presence of a trisubstituted double bond attached to an electron deactivating group. Signals for one olefin methine at $\delta_{\mathrm{H}} 4.98 \mathrm{ppm}(1 \mathrm{H}, \mathrm{br} \mathrm{t}, 7.25, \mathrm{H}-12)$, three methylene protons at $\delta_{\mathrm{H}} 2.43 \mathrm{ppm}(2 \mathrm{H}, \mathrm{m}, \mathrm{H}-11)$, $\delta_{\mathrm{H}} 1.74 \mathrm{ppm}, 1.83 \mathrm{ppm}(2 \mathrm{H}, \mathrm{m}, \mathrm{H}-14)$ and $\delta_{\mathrm{H}} 1.31 \mathrm{ppm}(2 \mathrm{H}, \mathrm{m}, \mathrm{H}-15)$, and two $s p^{2}$ methylene protons at $\delta_{\mathrm{H}} 4.71 \mathrm{ppm}$ and $4.85 \mathrm{ppm}(2 \mathrm{H}, \mathrm{br} \mathrm{s}, \mathrm{H}-18)$ were also present. On the other hand, four methyl groups in 
the aliphatic region at $\delta_{\mathrm{H}} 1.61 \mathrm{ppm}(3 \mathrm{H}, \mathrm{s}, \mathrm{H}-19), \delta_{\mathrm{H}} 1.27 \mathrm{ppm}(3 \mathrm{H}, \mathrm{s}, \mathrm{H}-20), \delta_{\mathrm{H}} 0.88 \mathrm{ppm}(3 \mathrm{H}, \mathrm{s}, \mathrm{H}-21)$, $\delta_{\mathrm{H}} 1.23 \mathrm{ppm}(3 \mathrm{H}, \mathrm{s}, \mathrm{H}-22)$, and one exchangeable $\mathrm{OH}$ signal $\left(\delta_{\mathrm{H}} 12.52 \mathrm{ppm}\right)$, could also be differentiated. The ${ }^{13} \mathrm{C}$ NMR spectrum of 1 (Table 2 and Figure S3) exhibited 25 signals: two carbonyl signals at $\delta_{\mathrm{C}}$ 189.7 and $195.5 \mathrm{ppm}$, two phenolic carbons ( $\delta_{C} 164.7$ and $\left.165.7 \mathrm{ppm}\right)$, ten $s p^{2}$ methine or quaternary carbon signals resonating between $\delta_{C} 107.7$ and $148.3 \mathrm{ppm}$, one $s p^{2}$ methylene at $\delta_{C} 110.3 \mathrm{ppm}$, one $s p^{3}$ oxygenated quaternary carbon a at $\delta_{C} 82.2 \mathrm{ppm}$, two oxygenated methine carbons at $\delta_{C} 65.8$ and 73.4 ppm, as well as other seven aliphatic methylene or methyl carbon signals with chemical shifts below $\delta_{C}$ $40.4 \mathrm{ppm}$. Summing up, according to a heteronuclear single quantum coherence spectroscopy (HSQC) experiment (multiplicity edited) (Figure S5), the ${ }^{13} \mathrm{C}$ NMR spectrum evidenced the presence of 4 methyl, 4 methylene, 6 methine, and 11 quaternary carbons. These NMR spectroscopic data suggested that compound $\mathbf{1}$ was structurally related to the napyradiomycin family of antibiotics, more precisely to dihydronapthoquinones with a 10-carbon monoterpenoid branched side chain (NPDs A series) [4]. A comparison of the NMR spectroscopic data of $\mathbf{1}$ with those of napyradiomycin A2a/A2b [6] revealed that 1 only differed from napyradiomycin $\mathrm{A} 2 \mathrm{a} / \mathrm{A} 2 \mathrm{~b}$ in the substitution at $\mathrm{C}-3$, with the replacement of the chlorine atom in the latter compound by a hydroxy group in $\mathbf{1}$ and the presence of an additional olefinic bond at C-4/C-4a. This double bond was easily located since the signals for $\mathrm{H}_{2}-4$ were lost and replaced by a $s p^{2}$ methine signal at $\delta_{\mathrm{H}} 6.89 \mathrm{ppm}$. Consequently, the ${ }^{13} \mathrm{C}$ NMR spectrum (Table 2 and Figure S3) showed two new olefinic carbons for C-4 and C-4a at $\delta_{C} 134.7 \mathrm{ppm}(\mathrm{CH})$ and $\delta_{\mathrm{C}} 137.6 \mathrm{ppm}$ (C). A comprehensive analysis of 2D NMR data (Figure 2 and Figure S4-S7) allowed the full planar structure of 1 to be assigned, being the first member of the napyradiomycin A-series bearing a hydroxy group rather than a chlorine at position C-3 of the dihydropyran ring (Figure 1).

Table 1. ${ }^{1} \mathrm{H}$ NMR $\left(500 \mathrm{MHz}\right.$ in DMSO- $\left.d_{6}\right)$ data for compounds 1-5.

\begin{tabular}{|c|c|c|c|c|c|}
\hline \multirow{2}{*}{ No. } & \multicolumn{5}{|c|}{$\delta^{1} \mathbf{H}($ mult, J, Hz) } \\
\hline & 1 & 2 & 3 & 4 & 5 \\
\hline \multicolumn{6}{|l|}{2} \\
\hline 3 & $3.72, \mathrm{~d}(6.4)$ & $4.98, \mathrm{~d}(1.6)$ & $4.70, \mathrm{~d}(6.9)$ & 4.38, dd $(11.8,4.4)$ & $4.40, \mathrm{dd}(11.8,4.4)$ \\
\hline \multirow[t]{2}{*}{4} & $6.89, \mathrm{~d}(6.4)$ & $6.73, \mathrm{~d}(1.6)$ & 7.01, d (6.9) & 2.12, dd $(13.4,4.4)$ & $2.25^{\mathrm{a}}, \mathrm{dd}(14.4,4.4)$ \\
\hline & & & & $2.19, \mathrm{dd},(13.4,11.8)$ & $2.52, \mathrm{dd}(14.4,11.8)$ \\
\hline $4 a$ & & & & $6.74, \mathrm{~s}$ & \\
\hline \multicolumn{6}{|l|}{5} \\
\hline \multicolumn{6}{|l|}{$5 a$} \\
\hline 6 & $12.52, \mathrm{~s}$ & $12.66, \mathrm{~s}$ & $12.56, \mathrm{~s}$ & $11.94, \mathrm{~s}$ & \\
\hline 7 & $6.57, \mathrm{~d}(2.1)$ & $6.59, \mathrm{~d}(2.2)$ & $6.60, \mathrm{~d}(1.9)$ & $6.66, \mathrm{~d}(2.0)$ & $7.04, \mathrm{~d}(2.4)$ \\
\hline 8 & - & - & - & - & - \\
\hline 9 & $6.84, \mathrm{~d}(2.1)$ & $6.88, \mathrm{~d}(2.2)$ & $6.88, \mathrm{~d}(1.9)$ & $6.99, \mathrm{~d}(2.0)$ & $7.18, \mathrm{~d}(2.4)$ \\
\hline \multicolumn{6}{|l|}{ 9a } \\
\hline \multicolumn{6}{|l|}{10} \\
\hline \multicolumn{6}{|l|}{$10 a$} \\
\hline \multirow[t]{2}{*}{11} & $2.43, \mathrm{~m}$ & $1.52^{\mathrm{a}}, \mathrm{dd}(13.3,3.4)$ & $1.68, \mathrm{dd}(15.2,2.4)$ & 1.27, br d $(16.4,2.3)$ & $2.26^{\mathrm{a}}, \mathrm{m}$ \\
\hline & & $1.85^{\mathrm{b}}, \mathrm{dd}(13.3,3.20)$ & $1.93, \mathrm{dd}(15.2,6.0)$ & $2.32, \mathrm{dd}(16.4,6.0)$ & $2.77, \mathrm{dd}(13.5,8.9)$ \\
\hline 12 & 4.98, br t $(7.25)$ & 1.31, br t $(3.3)$ & $1.60^{\mathrm{a}}, \mathrm{dd}(6.0,2.4)$ & $1.55, \mathrm{dd}(6.0,2.3)$ & 4.26, br t $(8.9)$ \\
\hline 13 & & $4.75, \mathrm{~s}$ & $4.40, \mathrm{~s}$ & $5.04, \mathrm{~s}$ & \\
\hline \multirow[t]{2}{*}{14} & $1.74, \mathrm{~m}$ & $1.46, \mathrm{~m}$ & $1.37, \mathrm{~m}$ & $1.47, \mathrm{~m}$ & $1.42, \mathrm{~m}$ \\
\hline & $1.83, \mathrm{~m}$ & $1.51^{\mathrm{a}}, \mathrm{m}$ & $1.60^{\mathrm{a}}, \mathrm{m}$ & $1.67, \mathrm{~m}$ & $1.93^{\mathrm{b}}, \mathrm{m}$ \\
\hline \multirow[t]{2}{*}{15} & $1.31, \mathrm{~m}$ & $1.70, \mathrm{dd}(13.5,12.1)$ & $1.70, \mathrm{dd}(13.2,12.1)$ & $1.72, \mathrm{~m}$ & $1.95^{\mathrm{b}}, \mathrm{m}$ \\
\hline & & $1.81^{\mathrm{b}}, \mathrm{dd}(13.5,3.8)$ & $1.83, \mathrm{dd}(13.2,3.1)$ & $1.82, \mathrm{~m}$ & \\
\hline
\end{tabular}


Table 1. Cont.

\begin{tabular}{|c|c|c|c|c|c|}
\hline \multirow{2}{*}{ No. } & \multicolumn{5}{|c|}{$\delta^{1} \mathrm{H}$ (mult, J, Hz) } \\
\hline & 1 & 2 & 3 & 4 & 5 \\
\hline 16 & $3.78, \mathrm{t}(6.2,6.2)$ & $4.02, \mathrm{dd}(12.1,3.8)$ & 3.77, dd $(12.1,3.1)$ & 3.81 , dd $(11.9,3.9)$ & 4.91, br t $(11.5,6.5)$ \\
\hline \multicolumn{6}{|l|}{17} \\
\hline \multirow[t]{2}{*}{18} & 4.71 , br s & $0.94^{\mathrm{c}}, \mathrm{s}$ & $1.02, \mathrm{~s}$ & $1.15, \mathrm{~s}$ & $4.67, \mathrm{~s}$ \\
\hline & 4.85, br s & & & & $4.73, \mathrm{~s}$ \\
\hline 19 & $1.61, \mathrm{~s}$ & $1.40, \mathrm{~s}$ & $1.42, \mathrm{~s}$ & $1.35, \mathrm{~s}$ & $1.37, \mathrm{~s}$ \\
\hline 20 & $1.27, \mathrm{~s}$ & $0.79, \mathrm{~s}$ & $0.91, \mathrm{~s}$ & $1.02, \mathrm{~s}$ & $1.11, \mathrm{~s}$ \\
\hline 21 & $0.88, \mathrm{~s}$ & $0.94^{\mathrm{c}}, \mathrm{s}$ & $0.77, \mathrm{~s}$ & $0.38, \mathrm{~s}$ & $1.32, \mathrm{~s}$ \\
\hline 22 & $1.23, \mathrm{~s}$ & $0.64, \mathrm{~s}$ & $0.63, \mathrm{~s}$ & $0.59, \mathrm{~s}$ & $1.52, \mathrm{~s}$ \\
\hline
\end{tabular}

Table 2. ${ }^{13} \mathrm{C}$ NMR (125 MHz in DMSO- $\left.d_{6}\right)$ data for compounds 1-5.

\begin{tabular}{|c|c|c|c|c|c|}
\hline \multirow{2}{*}{ No. } & \multicolumn{5}{|c|}{$\delta^{13} \mathrm{C}$} \\
\hline & 1 & 2 & 3 & 4 & 5 \\
\hline 2 & $75.4, \mathrm{C}$ & $76.1, \mathrm{C}$ & $74.8, \mathrm{C}$ & $79.1, \mathrm{C}$ & $78.2, \mathrm{C}$ \\
\hline 3 & $65.8, \mathrm{CH}$ & $59.9, \mathrm{CH}$ & $57.3, \mathrm{CH}$ & $58.9, \mathrm{CH}$ & $59.8, \mathrm{CH}$ \\
\hline 4 & $134.7, \mathrm{CH}$ & $136,2 \mathrm{CH}$ & $132.1, \mathrm{CH}$ & $40.4, \mathrm{CH}_{2}$ & $41.6 \mathrm{CH}_{2}$ \\
\hline $4 a$ & $137.6, \mathrm{C}$ & $136.3, \mathrm{C}$ & $137.8, \mathrm{C}$ & $79.2, C^{2}$ & 81.7, C \\
\hline 5 & $189.7, \mathrm{C}$ & 187.7, C & 188.3, C & $194.4, \mathrm{C}$ & 183.4, C \\
\hline $5 a$ & $110.8, \mathrm{C}$ & $110.5, \mathrm{C}$ & $110.4, \mathrm{C}$ & $107.9, \mathrm{C}$ & 116.7, C \\
\hline 6 & $164.7, \mathrm{C}$ & $164.8, \mathrm{C}$ & $164.8, \mathrm{C}$ & $163.9, \mathrm{C}$ & $162.7, \mathrm{C}$ \\
\hline 7 & $107.8, \mathrm{CH}$ & $108.1, \mathrm{CH}$ & $108.1, \mathrm{CH}$ & $108.5, \mathrm{CH}$ & $113.5, \mathrm{CH}$ \\
\hline 8 & $165.7, \mathrm{C}$ & 165.3, C & 165.6, C & $165.7, \mathrm{C}$ & 163.8, C \\
\hline 9 & 107.7, CH & 107.7, CH & 107.9, CH & 107.8, $\mathrm{CH}$ & 108.3, CH \\
\hline $9 a$ & $136.5, \mathrm{C}$ & $135.9, \mathrm{C}$ & $135.9, \mathrm{C}$ & 135.1, C & $136.4, \mathrm{C}$ \\
\hline 10 & $195.5, \mathrm{C}$ & $195.3, \mathrm{C}$ & $194.9, \mathrm{C}$ & $199.5, \mathrm{C}$ & 196.0, C \\
\hline $10 a$ & $82.2, \mathrm{C}$ & $82.9, \mathrm{C}$ & $82.6, \mathrm{C}$ & $83.7, \mathrm{C}$ & $82.9, \mathrm{C}$ \\
\hline 11 & $40.4, \mathrm{CH}_{2}$ & $37.0, \mathrm{CH}_{2}$ & $37.8, \mathrm{CH}_{2}$ & 33.7, $\mathrm{CH}_{2}$ & $41.5, \mathrm{CH}_{2}$ \\
\hline 12 & 117.7, CH & $50.5, \mathrm{CH}$ & $50.1, \mathrm{CH}$ & $48.6, \mathrm{CH}$ & $116.9, \mathrm{CH}$ \\
\hline 13 & $138.9, \mathrm{C}$ & $70.5, \mathrm{C}$ & $70.1, \mathrm{C}$ & $70.1, \mathrm{C}$ & $140.6, \mathrm{C}$ \\
\hline 14 & $35.5, \mathrm{CH}_{2}$ & $41.2, \mathrm{CH}_{2}$ & $41.3, \mathrm{CH}_{2}$ & $41.2, \mathrm{CH}_{2}$ & $39.7, \mathrm{CH}_{2}$ \\
\hline 15 & $32.9, \mathrm{CH}_{2}$ & $31.1, \mathrm{CH}_{2}$ & $30.8, \mathrm{CH}_{2}$ & $30.5, \mathrm{CH}_{2}$ & 23.7, $\mathrm{CH}_{2}$ \\
\hline 16 & $73.4, \mathrm{CH}$ & $72.2, \mathrm{CH}$ & $72.4, \mathrm{CH}$ & $71.8, \mathrm{CH}$ & $126.5, \mathrm{CH}$ \\
\hline 17 & 148.3, C & $40.4, \mathrm{C}$ & $40.4, \mathrm{C}$ & $40.2, \mathrm{C}$ & 129.2, C \\
\hline 18 & $110.3, \mathrm{CH}_{2}$ & $20.5, \mathrm{CH}_{3}$ & $25.8, \mathrm{CH}_{3}$ & 21.6, $\mathrm{CH}_{3}$ & $76.3, \mathrm{CH}_{2}$ \\
\hline 19 & $17.8, \mathrm{CH}_{3}$ & $26.5, \mathrm{CH}_{3}$ & $26.5, \mathrm{CH}_{3}$ & $28.7, \mathrm{CH}_{3}$ & $28.9, \mathrm{CH}_{3}$ \\
\hline 20 & $24.9, \mathrm{CH}_{3}$ & $23.6, \mathrm{CH}_{3}$ & $24.2, \mathrm{CH}_{3}$ & $24.4, \mathrm{CH}_{3}$ & $22.5, \mathrm{CH}_{3}$ \\
\hline 21 & $25.7, \mathrm{CH}_{3}$ & $30.1, \mathrm{CH}_{3}$ & $29.0, \mathrm{CH}_{3}$ & $28.4, \mathrm{CH}_{3}$ & $15.2, \mathrm{CH}_{3}$ \\
\hline 22 & $16.1, \mathrm{CH}_{3}$ & $16.6, \mathrm{CH}_{3}$ & $16.7, \mathrm{CH}_{3}$ & $16.0, \mathrm{CH}_{3}$ & $15.1, \mathrm{CH}_{3}$ \\
\hline
\end{tabular}

The relative stereochemistry of the dihydropyran ring of compound $\mathbf{1}$ (Figure 3) was assigned by interpretation of ROESY data (Figure S7) and the coupling constants observed in its ${ }^{1} \mathrm{H}$ NMR spectrum (Table 1, Figure S2) in combination with molecular modelling using Chem3D 12.0 Pro. The biosynthetic route for all napyradiomycins described to date was also considered $[3,28,29]$. The almost equally intense ROESY correlations observed between H-3 and both geminal methyl groups (C-20 and C-21) together with a coupling constant value of $6.4 \mathrm{~Hz}$ between protons $\mathrm{H}-3$ and $\mathrm{H}-4$ (Figure 3), in good agreement with a dihedral angle of $28.7^{\circ}$ measured in the energy-minimized molecular model (Figure S8), confirmed the relative configuration at C-3 of the dihydropyran ring in 1. Assuming an $R$ absolute configuration at $\mathrm{C}-10$ a based on the common biosynthetic origin described for the napyradiomycin A series described to date, the absolute configuration at $\mathrm{C}-3$ was also proposed to be 
$R$. Finally, the low amount of $\mathbf{1}$ obtained prevented the determination of the absolute configuration of the chiral center at C-16 using Mosher's approaches.

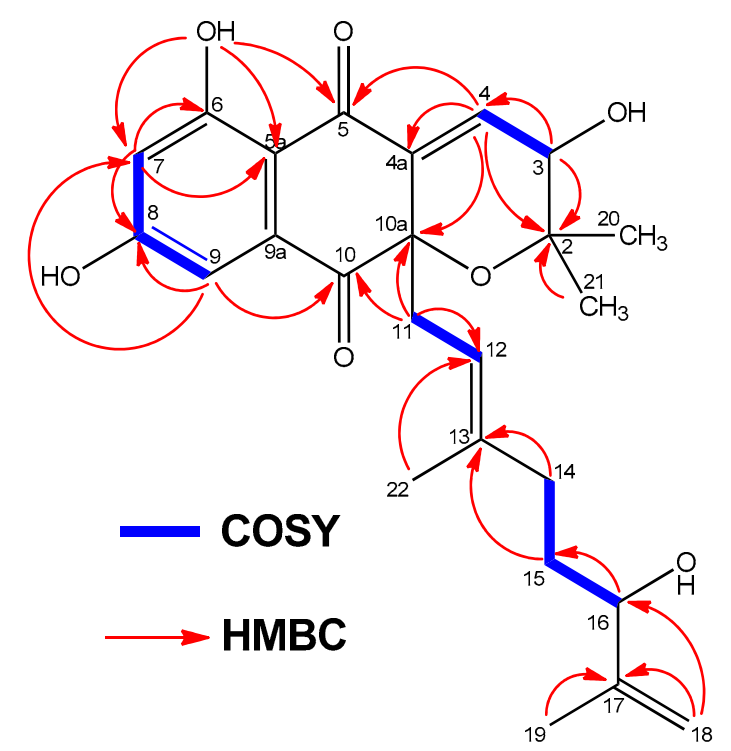

Figure 2. Key COSY and HMBC correlations observed in the spectra of compound $\mathbf{1 .}$

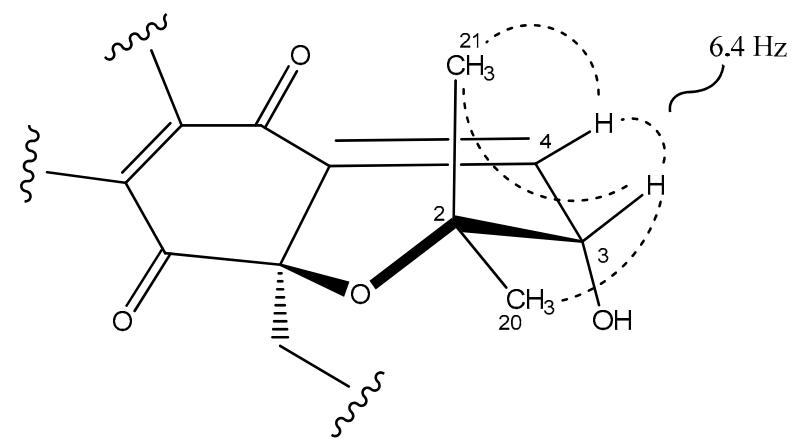

Figure 3. Key ROESY correlations (dashed lines) and coupling constant that determine the relative configuration of the dihydropyran ring in napyradiomycin A3 (1).

Compounds 2 and 3 were isolated as white powders and their molecular formula was determined to be $\mathrm{C}_{25} \mathrm{H}_{30} \mathrm{Cl}_{2} \mathrm{O}_{6}$ on the basis of HRMS measurements (Figures S9-A and S18-A) (ESI-TOFMS $\mathrm{m} / \mathrm{z}$ $479.1389\left[\mathrm{M}+\mathrm{H}-\mathrm{H}_{2} \mathrm{O}\right]^{+}$for compound 2 and $479.1394\left[\mathrm{M}+\mathrm{H}-\mathrm{H}_{2} \mathrm{O}\right]^{+}$for compound 3, calcd. for $\left.\mathrm{C}_{25} \mathrm{H}_{29}{ }^{35} \mathrm{Cl}_{2} \mathrm{O}_{5}{ }^{+}, 479.1387\right)$. This formula requires 10 degrees of unsaturation. Their UV, IR, and NMR spectroscopic data were almost identical and shared common features. The UV absorption pattern (Figures S9-B and S18-B) along with the IR spectrum of both (broad absorption bands at around $3294 \mathrm{~cm}^{-1}$ for multiple hydroxyl groups, and at $1701 \mathrm{~cm}^{-1}$ for a conjugated carbonyl functionality) suggested that these compounds also possessed the dihydronaphthoquinone moiety present in napyradiomycin metabolites. Comprehensive analysis of 1D and 2D NMR data of compounds 2 (Tables 1 and 2; Figures S10-S16) and 3 (Tables 1 and 2; Figures S19-S25) revealed a strong similarity between them and evidenced that they were epimers at C-3 position of the dihydropyran ring.

Interpretation of 2D NMR data of compound 2 allowed all the protons and carbons to be assigned and according to a HSQC experiment (multiplicity edited) (Figure S13), we distinguished the presence of 5 methyl, 3 methylene, 6 methine, and 11 quaternary carbons. These NMR spectroscopic data suggested that compound 2 was structurally related to dihydronapthoquinones with the monoterpenoid substituent cyclized to a 6-membered ring (NPDs B series) [4]. The dihydronaphtoquinone ring was constructed based on HMBC correlations (Figure 4 and Figure S14) from H-9 $\left(\delta_{\mathrm{H}} 6.88 \mathrm{ppm}\right.$ ) to C-5a, 
C-7, C-8, and C-10, and from OH-6 $\left(\delta_{\mathrm{H}} 12.66 \mathrm{ppm}\right)$ to C-5a, C-6, and C-7. In addition, correlations in the HMBC experiment between the two geminal methyl groups $\mathrm{H}_{3}-18$ and $\mathrm{H}_{3}-19\left(\delta_{\mathrm{H}} 0.94\right.$ and $\delta_{\mathrm{H}}$ $1.40 \mathrm{ppm}$ ) and C-2 and C-3, and between the olefinic proton $\mathrm{H}-4$ at $\delta_{\mathrm{H}} 6.73 \mathrm{ppm}$ and C-2, C-3, C-4a, and $\mathrm{C}-10 \mathrm{a}$ indicated the presence of a dihydropyran ring and confirmed the position of a chlorine substituent at $\mathrm{C}-3\left(\delta_{\mathrm{H}} 4.98, \mathrm{~s} ; \delta_{\mathrm{C}} 59.9, \mathrm{CH}\right)$ and a trisubstituted double bond at $\Delta^{4,4 a}$. Analysis of the overall NMR data set (Tables 1 and 2; Figures S10-S16) for the monoterpene unit (C-11 to C-17 and C-20, C-21, and C-22) in 2 showed that it was a cyclohexane ring with a chair conformation. Based on these NMR features, the planar structure of 2 was established (Figure 4). A similar analysis of the NMR data set (Tables 1 and 2; Figures S19-S25) for compound 3 rendered the same planar structure and evidenced the close structural similarity of $\mathbf{2}$ and $\mathbf{3}$ with the previously reported antibiotic CNQ525.510A, which is additionally methylated at C-7 [3].

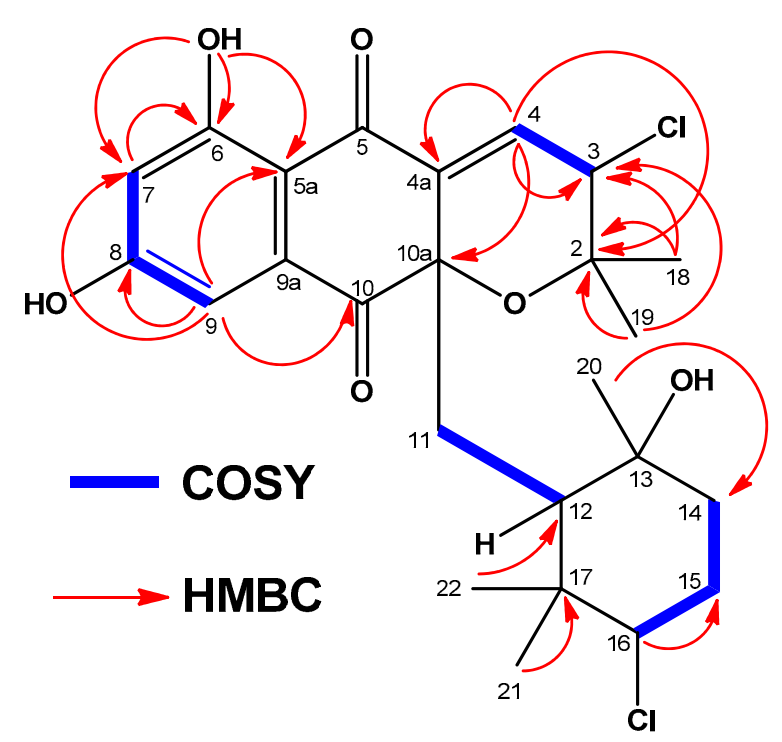

Figure 4. Key COSY and HMBC correlations observed in the spectra of compound 2 or 3.

The relative stereochemistry of $\mathbf{2}$ and $\mathbf{3}$ was assigned by analysis of NOESY and ROESY NMR data (Figures S15, S16, S24, and S25) and the coupling constants observed in their ${ }^{1} \mathrm{H}$ NMR spectra. NOESY correlations between the $\mathrm{H}_{3}-21$ methyl protons and the methine protons $\mathrm{H}-12$ and $\mathrm{H}-16$ showed these protons were on the same face of the cyclohexane ring in both compounds (Figure 5). A ROESY correlation between the $\mathrm{H}_{3}-20$ and $\mathrm{H}_{3}-22$ methyl groups determined their axial orientation on the bottom face of the ring. Finally, based on the existence of a strong ROESY correlation, H-12 and H-16 were positioned in a 1,3-diaxial position on the top face of the ring (Figure 5).

Regarding the dihydropyran ring, we used the vicinal ${ }^{3} J_{\mathrm{HH}}$ spin-spin coupling constants and key NOESY correlations to establish the relative configuration of this moiety. The coupling constant between the olefinic proton at $\mathrm{H}-3$ and its vicinal proton $\mathrm{H}-4$ in 2 had a value of $1.6 \mathrm{~Hz}$ (Figure 6), which is in good agreement with a dihedral angle of $91.4^{\circ}$ measured in the energy-minimized molecular model (Figure S17). Furthermore, only one NOESY correlation is observed between H-3 and one of the geminal methyl groups $\left(\mathrm{H}_{3}-19\right)$, due to the antiperiplanar position of the $\mathrm{H}_{3}-18$ methyl with respect to H-3 (Figure 6 and Figure S15). Thus, the relative configuration on the dihydropyran ring for compound 2 was confirmed as depicted in Figure 1. Conversely, the almost equally intense and strong $n O e$ correlations observed between $\mathrm{H}-3$ and both geminal methyl groups (C-18 and C-19) in the spectra of 3 (Figure 6 and Figure S24), together with a coupling constant value of $6.9 \mathrm{~Hz}$ between protons $\mathrm{H}-3$ and $\mathrm{H}-4$ in accordance with a dihedral angle of $25.2^{\circ}$ measured in the energy-minimized molecular model (Figure S26), confirmed the opposite relative configuration at C-3 for compound 3. 


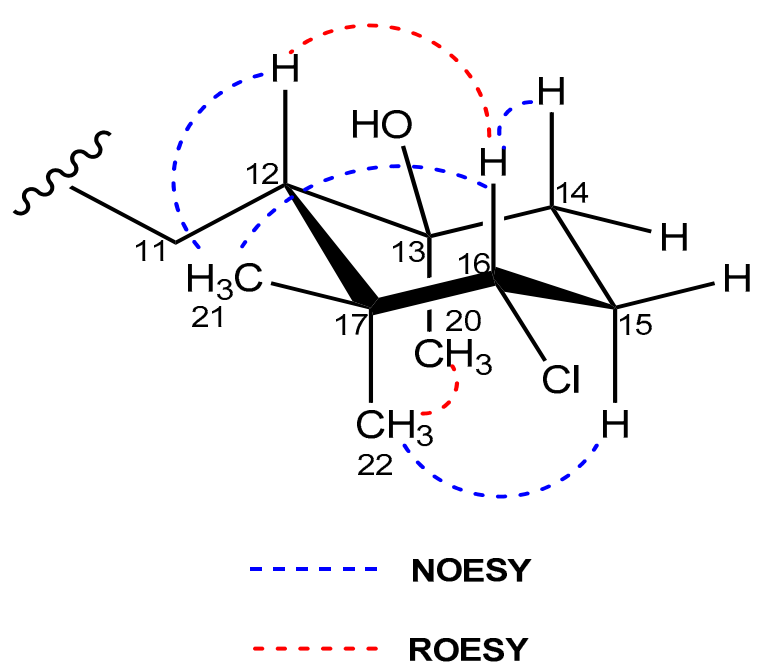

Figure 5. Key NOESY/ROESY correlations that determine the relative configuration of the cyclohexane ring in compounds 2 and 3.

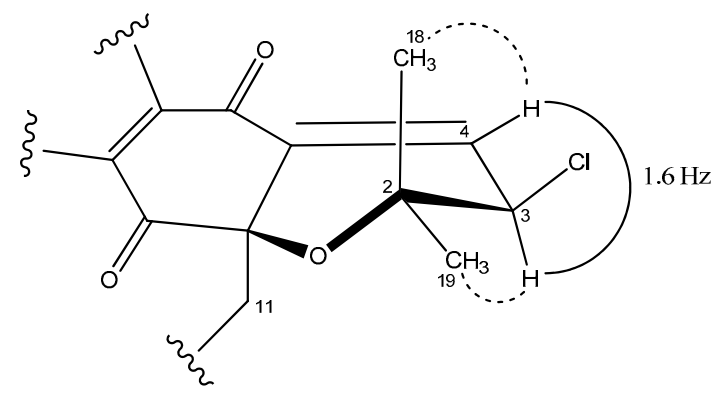

Napyradiomycin B7a (2)

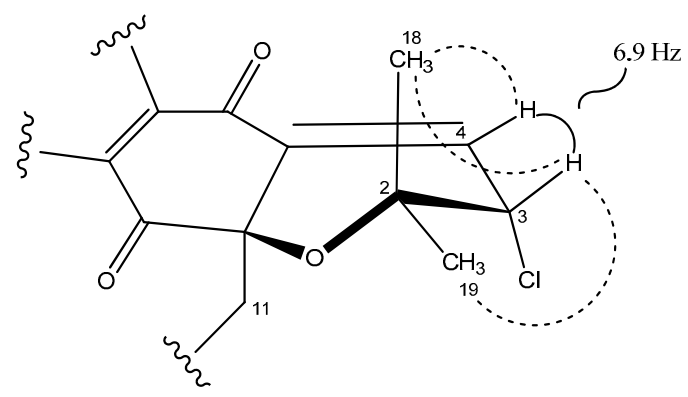

Napyradiomycin B7b (3)

Figure 6. Key NOESY correlations (dashed lines) and coupling constants that determine the relative configuration of the dihydropyran ring in compounds 2 and 3.

The absolute configurations of $\mathbf{2}$ and $\mathbf{3}$ were assumed to be the same as those reported for all the napyradiomycins in the B series. Apart from the common biosynthetic origin, this proposal was additionally supported by the comparison of specific rotation data. The sign of the specific rotation for compound 2 is negative $\left([\alpha]_{25}^{\mathrm{D}}-41.0^{\circ}, c 0.4, \mathrm{MeOH}\right)$, as is that reported for CNQ525.510A [3], which is a C-7 methylated version of 2 . On the contrary, the sign of $[\alpha]_{25}^{\mathrm{D}}$ value for the epimeric compound 3 is positive $\left([\alpha]_{25}^{\mathrm{D}}+32.0^{\circ}, c 0.13, \mathrm{MeOH}\right)$. The previously reported B-type napyradiomycin MDN-0170 [23] displays the same relative configuration at C-3 (but bearing a hydroxy group instead of a chlorine atom), and showed a positive value of specific rotation, providing evidence of the same absolute configuration.

Compound 4 was obtained as a white powder. The complex pattern of the ion clusters in the adducts of its ESI mass spectrum (Figure S27-A) clearly indicated the presence of two chlorine atoms in the molecule. ESI-TOFMS analysis (Figure S27-B) suggested the molecular formula $\mathrm{C}_{25} \mathrm{H}_{32}{ }^{35} \mathrm{Cl}_{2} \mathrm{O}_{7}(\mathrm{~m} / \mathrm{z}$ 497.1498 [M+ $\left.\mathrm{H}-\mathrm{H}_{2} \mathrm{O}\right]^{+}$, calcd. for $\mathrm{C}_{25} \mathrm{H}_{31}{ }^{35} \mathrm{Cl}_{2} \mathrm{O}_{6}{ }^{+}$, 497.1492), indicating nine degrees of unsaturation. Analysis of combined ${ }^{1} \mathrm{H}$ and ${ }^{13} \mathrm{C}$ NMR spectroscopic data (Tables 1 and 2; Figures S28-S33) showed signals similar to those of napyradiomycin metabolites. The presence of a tetrahydropyran ring fused to the dihydronaphthoquinone moiety in 4 was clearly evidenced from the absence of the olefinic proton signal at C-4 present in compounds 1-3, now replaced by two new diastereotopic protons at $\delta_{\mathrm{H}} 2.12$ and 2.19 at that position. Furthermore, the presence of a hydroxy substituent at $C-4 a$, easily assigned based on HMBC correlations (Figure S32) of that OH-4a at $\delta_{\mathrm{H}} 6.74$ with C-4, C-4a, C10, and C-10a that 
corroborates the presence of this tetrahydropyran ring. Comprehensive NMR analyses allowed all protons and carbons to be assigned, and compound 4 was confirmed to be napyradiomycin SC, whose structure was incompletely reported by Kamimura and co-workers in a Japanese patent in 1997 [27]. Details on how the structure was assigned, spectroscopic data, and the absolute stereochemistry of compound 4 were never reported.

The relative stereochemistry of 4 was assigned by analysis of NOESY data (Figure 7 and Figure S33). Correlations of the protons on the cyclohexane ring were identical to those observed in the NOESY/ROESY experiments for 2 and 3. Key NOESY correlations between the exchangeable $\mathrm{OH}$ signal at C-4a with both $\mathrm{H}-11$ protons and the methine $\mathrm{H}-12$ indicated that the tetrahydropyran ring was cis-fused to the dihydroquinone, as observed for other napyradiomycins. A correlation observed between the $\mathrm{OH}-4 \mathrm{a}$ hydroxy group and the methine $\mathrm{H}-3$ indicated that these were both oriented on the bottom face of the tetrahydropyran ring. The typical axial-equatorial coupling constants measured between $\mathrm{H}-3(J=11.8,4.4 \mathrm{~Hz})$ and the methylene proton pair $\mathrm{H}_{2}-11$ are in good agreement with dihedral angles of $-172.6^{\circ}$ and $-55.3^{\circ}$ measured in the energy-minimized molecular model (Figure S34) and confirm that the tetrahydropyran ring was in a chair form, identical to the configuration of this ring in the crystal structure of napyradiomycin B4 [8], a methylated version of compound 4 bearing a chlorine instead of a hydroxy group at C-4a. The full stereostructure of napyradiomycin B4 was assigned by X-ray diffraction methods [8] and hence, the absolute setereochemistry is assumed identical to that of napyradiomycin B4 based on comparable specific rotation values. The sodium D line specific rotations of compound $4\left([\alpha]_{25}^{\mathrm{D}}-43.0^{\circ}, c 0.4, \mathrm{MeOH}\right)$ and napyradiomycin $\mathrm{B} 4\left([\alpha]_{25}^{\mathrm{D}}-190^{\circ}\right.$, $\left.c 0.031, \mathrm{CHCl}_{3}\right)$ are both negative, providing evidence that both compounds should possess the same absolute configuration.

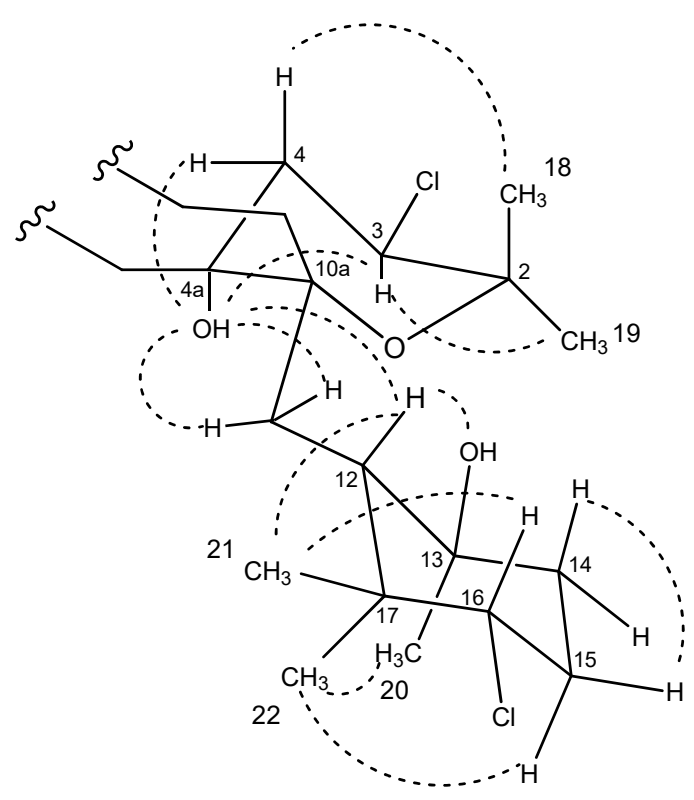

Figure 7. Conformation in solution of compound 4 based upon NOESY analysis.

Compound 5 was obtained as a white powder and was assigned the molecular formula $\mathrm{C}_{25} \mathrm{H}_{28} \mathrm{Cl}_{2} \mathrm{O}_{5}$ by evaluation of HRMS data (Figure S35-A) (ESI-TOFMS m/z 479.1384 [M + H] ${ }^{+}$, calcd. for $\left.\mathrm{C}_{25} \mathrm{H}_{29}{ }^{35} \mathrm{Cl}_{2} \mathrm{O}_{5}{ }^{+}, 479.1387\right)$. The overall analysis of its NMR spectroscopic data (Tables 1 and 2; Figures S36-S41) clearly showed that the compound possesses the characteristic dihydronaphthoquinone moiety of napyradiomycins, fused to a tetrahydropyran ring and bearing a linear monoterpenoid attached to its C-10a carbon. The ${ }^{1} \mathrm{H}$ NMR spectrum of 5 (Table 1, Figure S36) exhibited, among other signals, four singlet methyl groups $\left(\delta_{\mathrm{H}} 1.11,1.32,1.37\right.$, and 1.52 ppm), two doublets from aromatic protons $\left(\delta_{\mathrm{H}} 7.04\right.$ and $\left.7.18 \mathrm{ppm}\right)$, one methine proton geminal to a 
chlorine atom $\left(\delta_{\mathrm{H}} 4.40 \mathrm{ppm}\right)$ and two signals from olefinic methine groups ( $\delta_{\mathrm{H}} 4.26$ and $\left.4.91 \mathrm{ppm}\right)$. Interestingly, compound 5 lacks the characteristic deshielded singlet signal of $\mathrm{OH}-6$. HMBC correlations (Figure S40-A) from H-3 ( $\left.\delta_{\mathrm{H}} 4.40 \mathrm{ppm}\right)$ to $\mathrm{C}-19 / \mathrm{C}-20, \mathrm{C}-2$, and C-4a, and from $\mathrm{H}_{2}-4\left(\delta_{\mathrm{H}} 2.52,2.25 \mathrm{ppm}\right)$ to $\mathrm{C}-2, \mathrm{C}-3, \mathrm{C}-4 \mathrm{a}, \mathrm{C}-5$, and $\mathrm{C}-10 \mathrm{a}$ defined the presence of the archetypal tetrahydropyran ring with two chlorine substituents at C-3 and C-4a positions reported for other napyradiomycins such as 18-hydroxynapyradiomycin A1 (10) [6], napyradiomycin A2a (11) [6], napyradiomycin A2b (12) [6], or napyradiomycin B4 (13) [8]. COSY NMR spectroscopic data (Figure S38) allowed the identification of three key proton spin systems within the monoterpenoid moiety: $\mathrm{H}_{2}-11 / \mathrm{H}-12, \mathrm{H}_{2}-14 /-\mathrm{H}_{2}-15 / \mathrm{H}-16$, and $\mathrm{H}_{2}-18$ (Figure 8). These three proton sequences were connected as a linear monoterpenoid side chain by interpretation of HMBC correlations (Figure 8 and Figure S40) from $\mathrm{H}_{3}-21$ to C-12, C-13, and C-14, and from $\mathrm{H}_{3}-22$ to $\mathrm{C}-16, \mathrm{C}-17$, and C-18. As expected, additional $\mathrm{HMBC}$ correlations from both $\mathrm{H}_{2}-11$ and $\mathrm{H}-12$ clearly established the attachment of this side chain to C-10a of the dihydronaphthoquinone moiety (Figure 8). All these assignments accounted for ten of the eleven degrees of unsaturation and indicated that $\mathbf{5}$ was composed of a tetracyclic ring system, evidencing that $\mathbf{5}$ is closely related to napyradiomycin $\mathrm{C} 1$ and other compounds within the $C$ series $[1,26]$.

The chemical shift of the methylene carbon signal C-18 $\left(\delta_{\mathrm{C}} 76.3 \mathrm{ppm}\right)$ strongly supported the presence of an oxygen substituent at this position. Moreover, the deshielding of this carbon signal in comparison with that found for 18-hydroxynapyradiomycin $A 1(10)\left(\delta_{C} 66.6 \mathrm{ppm}\right)$ suggested the etherification of the 18-hydroxy groups in 5. Finally, the strong key $\mathrm{HMBC}$ correlation from $\mathrm{H}_{2}-18$ to C-6 $\left(\delta_{C} 162.7 \mathrm{ppm}\right.$; Figure $\left.540 \mathrm{~b}\right)$ allowed us to establish unambiguously the existence of such ether link between C- 6 and C-18, which results in a 14-membered bridging macrocycle between C- 6 and C-10a (Figure 8). This kind of O-linked cyclization has no precedent within the napyradiomycin metabolites, and therefore compound 5 represents the first member of a new subfamily of napyradiomycins, the D series. Thus, we propose the name napyradiomycin D1 for compound 5.

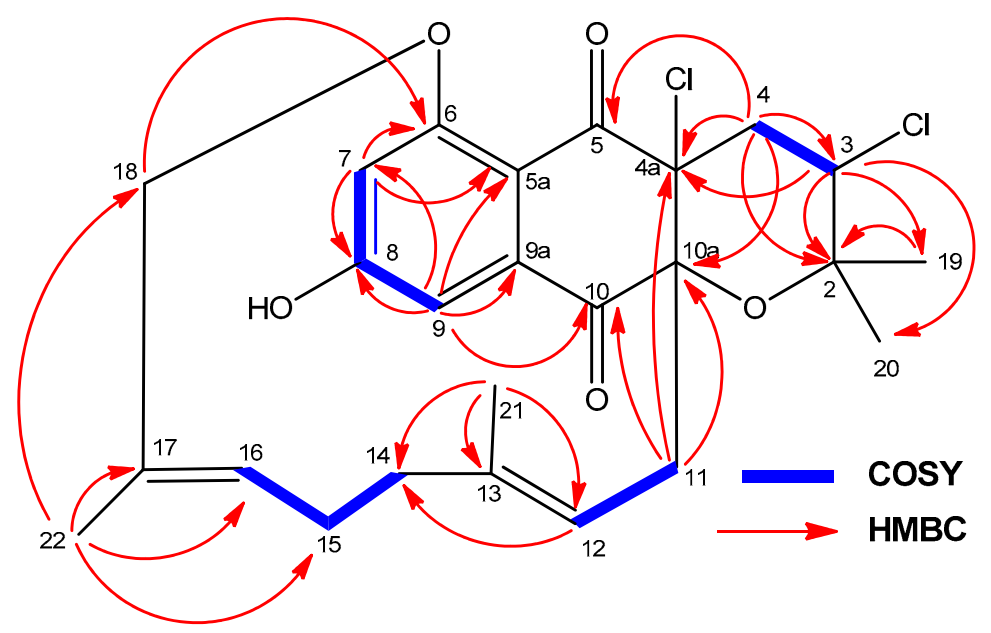

Figure 8. Key COSY and HMBC correlations observed in the spectra of compound 5.

The relative configuration of 5 was determined by inspection of the NOESY correlations and multiplet analysis for some key proton signals (Figure 9). As in napyradiomycin SC (4), the values of the coupling constants between $\mathrm{H}-3$ and the pair $\mathrm{H}_{2}-4(\mathrm{~J}=11.8,4.4 \mathrm{~Hz})$ confirmed a chair conformation of the tetrahydropyran ring and the axial orientation of $\mathrm{H}-3$. Although the substitution at $\mathrm{C}-4 \mathrm{a}$ with a chlorine atom in 5 prevents establishing a relative configuration with respect to C-10a, it was assumed to be cis, as for all tetrahydropyran-containing napyradiomycins described to date. The geometry of the two double bonds in $\mathbf{5}$ was assigned as $E$ based on the existence of NOESY cross-peaks between $\mathrm{H}_{2}-11 / \mathrm{H}_{3}-21 / \mathrm{H}_{2}-14$ and $\mathrm{H}-15 / \mathrm{H}_{3}-22 / \mathrm{H}_{2}-18$, as well as the absence of correlations between $\mathrm{H}-12 /$ $\mathrm{H}_{3}-21$ and $\mathrm{H}-16 / \mathrm{H}_{3}-22$ (Figure $9 \mathrm{a}$ ). The absolute configuration of 5 is assumed to be the same as for 
napyradiomycin C1 considering the comparable specific rotation values and the common biosynthetic origin [1].

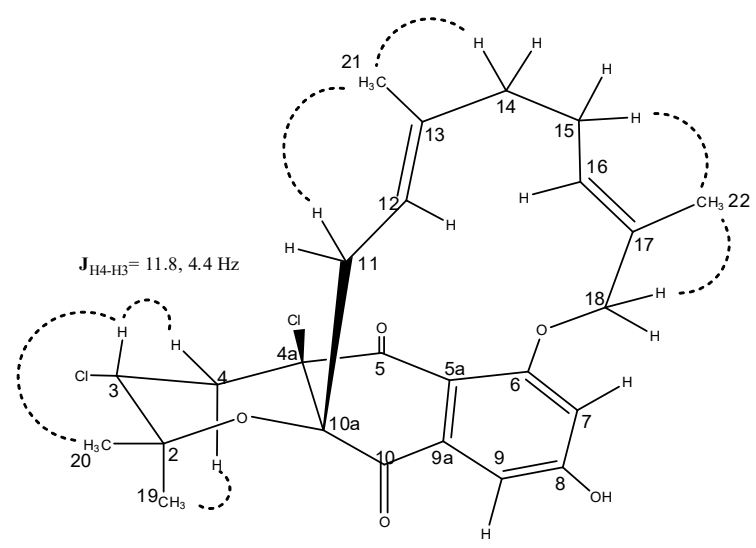

(a)

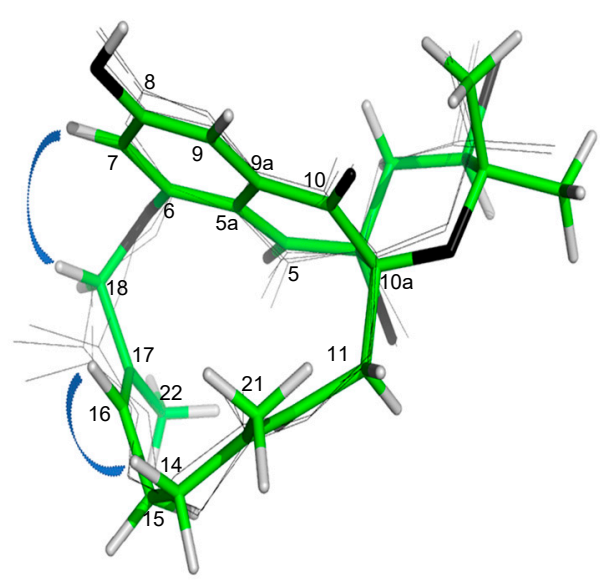

(b)

Figure 9. (a) Key NOESY correlations (dashed lines) supporting the relative configuration of napyradiomycin D1 (5). (b) Minimum-energy conformer for $\mathbf{5}$ and consistent $n O e$ cross-peaks.

Apart from the unambiguous NOESY correlations described above, other sets of cross-peaks were observed for proton signals within the linear monoterpenoid chain (Figure S41). The slight broadening for these signals in the ${ }^{1} \mathrm{H}$ NMR spectrum and the presence of such different sets of $n O e$ correlations clearly points to a fast (in NMR time-scale) conformational equilibrium in solution for 5 . Not surprisingly, this interconversion might be assisted by the flexibility of the terpenoid chain due to the presence of seven rotatable bonds within it. To better illustrate this, a conformational search using ConfBuster Web Server, a recently delivered open-source tool for the conformational analysis of macrocycles was launched [30]. As a result, up to four close-energy conformers were obtained (Figure S42), differing to each other in about $1.5 \mathrm{kcal} / \mathrm{mol}$, which supports the rapid interconversion between them. Interestingly, the minimum-energy conformer proved to be consistent with the most abundant one, as evidenced by the more intense set of NOESY cross-peaks between $\mathrm{H}_{2}-18$ (4.67 ppm) and the aromatic proton at $\mathrm{H}-7$ (7.04 ppm), and between the olefinic proton $\mathrm{H}-16$ (4.91 ppm) and $\mathrm{H}_{2}-14$ (1.42 ppm) (Figure 9b).

\subsection{Evaluation of Antimicrobial Activity}

Antibacterial, Antifungal, and Cytotoxic Activities

Compounds 1-15 were evaluated for their antibacterial and antifungal properties against a clinical isolate of methicillin resistant Staphylococcus aureus (MRSA), Mycobacterium tuberculosis, Escherichia coli, Acinetobacter baumannii, and Aspergillus fumigatus (Table 3). Napyradiomycins 2, 5, 7, 12, 13, 14, and 15 showed antibacterial activities against MRSA with MIC values ranging from 3 to $48 \mu \mathrm{g} / \mathrm{mL}$. The new napyradiomycin D1 (5) was one of the most active compounds and displayed activities comparable to those of napyradiomycin B4 (13) and napyradiomycin B5 (15). Napyradiomycin A2b (12) and napyradiomycin B2 (14) exhibited the best antibacterial activities (MIC values of 3-6 $\mu \mathrm{g} / \mathrm{mL}$ ) among these fifteen napyradiomycins. Except compounds 3, 6, 8, and 10, the other ten napyradiomycins isolated showed moderate activity against the Gram-positive bacteria M. tuberculosis H37Ra with MIC values fluctuating from 12 to $48 \mu \mathrm{g} / \mathrm{mL}$. None of the compounds exhibited activity against the Gram-negative bacteria E. coli ATCC 25922 or A. baumannii MB5973 neither against the fungus A. fumigatus ATCC 46645. 
Eight napyradiomcins, 2, 5, 8, 11, 12, 13, 14, and 15 showed moderate cytotoxic activities with $\mathrm{IC}_{50}$ values below $50 \mu \mathrm{M}$ against the human liver adenocarcinoma cell line (HepG-2), whereas the other seven had reduced cytotoxicities, with $\mathrm{IC}_{50}$ values above this concentration.

Table 3. Antibacterial, antifungal, and cytotoxic activities of compounds 1-15.

\begin{tabular}{|c|c|c|c|c|c|c|}
\hline & \multicolumn{5}{|c|}{$\operatorname{MIC}(\mu \mathrm{g} / \mathrm{mL})$} & \multirow{2}{*}{$\frac{\mathrm{IC}_{50}(\mu \mathrm{M})}{\text { HepG-2 }}$} \\
\hline & MRSA & $M t$ & $E c$ & $A b$ & $A f$ & \\
\hline 1 & $>96$ & $\mathrm{NT}^{\mathrm{a}}$ & $>96$ & $>96$ & $\mathrm{NT}^{\mathrm{a}}$ & $>67.8$ \\
\hline 2 & 48 & $12-24$ & $>96$ & $>96$ & $>96$ & 41.7 \\
\hline 3 & $>64$ & $>64$ & $>64$ & $>64$ & $>64$ & 109.5 \\
\hline 4 & $>96$ & $24-48$ & $>96$ & $>96$ & $>96$ & 263.5 \\
\hline 5 & $12-24$ & $24-48$ & $>96$ & $>96$ & $\mathrm{NT}^{\mathrm{a}}$ & 14.9 \\
\hline 6 & $>96$ & $>96$ & $>96$ & $>96$ & $>96$ & 277.2 \\
\hline 7 & $48-96$ & $12-24$ & $>96$ & $>96$ & $>96$ & 186.9 \\
\hline 8 & $>64$ & $>64$ & $>64$ & $>64$ & $>64$ & 30.2 \\
\hline 9 & $48-96$ & $12-24$ & $>96$ & $>96$ & $>96$ & 71.2 \\
\hline 10 & $48-96$ & $>96$ & $>96$ & $>96$ & $>96$ & 64.4 \\
\hline 11 & $12-24$ & $48-96$ & $>96$ & $>96$ & $>96$ & 30.4 \\
\hline 12 & $12-24$ & $48-96$ & $>96$ & $>96$ & $>96$ & 28.6 \\
\hline 13 & $12-24$ & $12-24$ & $>96$ & $>96$ & $>96$ & 15.6 \\
\hline 14 & $3-6$ & $24-48$ & $>96$ & $>96$ & $>96$ & 27.1 \\
\hline 15 & $12-24$ & $24-48$ & $>96$ & $>96$ & $>96$ & 40.1 \\
\hline
\end{tabular}

Note: MRSA, Methicillin-resistant Staphylococcus aureus MB5393; Mt, Mycobacterium tuberculosis H37Ra; Ec, Escherichia coli ATCC 25922; Ab, Acinetobacter baumannii MB5973; Af, Aspergillus fumigatus ATCC 46645. ${ }^{\text {a }}$ NT = not tested.

\section{Discussion}

The napyradiomycins constitute a large class of unique halogenated meroterpenoids, with around fifty members reported to date, produced by marine and terrestrial Streptomyces species [1-13]. The biosynthetic gene cluster (BGC) of napyradiomycins was first described from Streptomyces aculeolatus NRRL 18422 and from the marine derived Streptomyces sp. CNQ-525, and its analysis established the link between the presence of three vanadium-dependent haloperoxidases (VHPOs), (NapH1, NapH3, and NapH4) and a chloronium-induced meroterpene cyclization pathway [28]. The full biosynthetic route to these metabolites from three precursors (1,3,6,8-tetrahydroxynaphthalene, dimethylallyl pyrophosphate, and geranyl pyrophosphate), has been recently described and highlights the key role of those VHPO enzymes [29].

The final structures resulting from this biosynthetic pathway, the napyradiomycins, are hybrid terpenoid/polyketide metabolites composed of a semi-naphthoquinone chromophore, a prenyl unit attached to $\mathrm{C}-4 \mathrm{a}$ which is cyclized to produce a tetrahydropyran or dihydropyran ring and a monoterpenoid subunit attached at C-10a, which in turn can be either linear (type A napyradiomycins) or cyclized to 6-membered (type B) or to 14-membered (type C) rings. The different halogenation patterns add complexity and contribute to structural variations of these interesting metabolites [1-13]. A further proof of the still surprising structural possibilities for these natural products is the herein reported isolation of four new napyradiomycins, A3 (1), B7a (2), B7b (3), and D1 (5), showing unusual substitution patterns, inverted configuration of some chiral centers, or unprecedented cyclic bridging links.

Compound $\mathbf{1}$ is to the best of our knowledge the first example of a napyradiomycin in the A series bearing a hydroxy group instead a chlorine atom at position C-3 of the dihydropyran ring. This substitution pattern has been previously reported for napyradiomycins of types B (MDN-0170) [23] and $C[1,26]$, further displaying the same relative configuration as $\mathbf{1}$ at this chiral center. The presence of the C-3 hydroxy group with this absolute configuration can be explained considering the precursor of 1 might be the corresponding chlorinated compound at the same position, and that a non-enzymatic $\mathrm{S}_{\mathrm{N}} 2$ nucleophilic substitution with water on the C-3 chloride would result in the production of 1 . 
Compounds 2 and 3 are epimers at C-3 of their dihydropyran ring. The relative configuration at this chlorinated position for compound 3 is reported herein for the first time in the napyradiomycin series, since all the natural products of this family found in the literature or databases have the opposite configuration at the same chiral center (i.e., that found for compound 2) when it has a chlorine substituent. A first tentative explanation for this variant arises from the proposed mechanism of oxidative halogenation and subsequent halonium-induced cyclization in meroterpenoids [28]. Although the vanadium-dependent chloroperoxidase (VCPO) NapH1 has been shown to act in a stereoselective fashion when introducing chlorine atoms in napyradiomycin biosynthetic intermediates, it was also found that the same enzyme catalyzed a non-stereoselective bromination of the same substrate [31]. This result was explained because of the production of a diffusible hypobromous acid, which would depart the active site of the enzyme and then would brominate the substrate in a nonspecific manner. Indeed, the involvement of a hypohalous acid (HOX species) in this mechanism is widely accepted for vanadium-dependent haloperoxidases (VHPOs) from algae and fungi, which do not exhibit specificity [32], while for VCPOs from Streptomycetes it has been postulated that an enzyme-bound chlorine species would make possible the stereoselective halogenation [33,34].

The isolation herein of both diastereomeric versions of the same chlorinated product (compounds 2 and 3) could suggest the participation of a hypochlorous acid mediated chlorination along with the enzyme-assisted mechanism. However, the fact that this nonspecific chlorination has not been observed for any other napyradiomycin derivatives isolated in this work, i.e. from the same culture and therefore under the same conditions, did not support this overall hypothesis.

The other possibility is that the chlorine atom at C-3 in compound 3 may come from a $\mathrm{S}_{\mathrm{N}} 2$ displacement, therefore with inversion of configuration. The only reasonable way for that to occur is that a chloride ion is displacing the C-3 chlorine in compound 2. Although it is known that chloride is a poor nucleophile (and a fair leaving group), the activation of this allylic position within the dihydropyran ring could provide enough driving force for the reaction to proceed. Despite this epimerization has not been observed for any other dihydropyran ring-containing napyradiomycin (isolated in this work or not), we consider that the nucleophilic substitution to produce compound 3 may be the most plausible hypothesis.

Finally, compound 5 presents in its structure a 16-membered macrocycle because of a bridging ether link between C- 6 of the dihydronaphtoquinone unit and C-18 of the monoterpenoid chain. This kind of ether link is unprecedented within the napyradionmycin family, and therefore compound 5 represents the first member reported of a new series of napyradiomycins that we have designated as napyradiomycin D1. Remarkably, although a similar 15-membered cyclic ether ring has been previously reported for merochlorin $\mathrm{C}$ - a compound belonging to another family of meroterpenoid metabolites [35] - the O-linked bridging observed in 5 still represents, to the best of our knowledge, one of the largest ether cyclization events observed for a natural product. Regarding its biosynthesis, since NapH1 has been proved responsible for the halogenation and the formation of a 6-membered cyclic ether ring in napyradiomycins [31], it is tempting to think that the same enzyme could also catalyze this macrocyclization. However, the attachment in napyradiomycin D1 of the ether linkage to a former methyl group without the installation of any chiral chlorinated center vicinal to the linking position is inconsistent with a chloronium-induced cyclization catalyzed by NapH1. The whole genome sequencing of the producer strain CA-271078 and the inspection of its napyradiomycin BGC may further provide valuable data about this and other biosynthetic questions raised in this work.

Although the specific mechanism of action for this family of meroterpenoids is not totally clear $[5,14,15]$, previous studies about the structure activity relationship (SAR) have shown that structural variations among the napyradiomycin metabolites scaffold known so far, such as the different halogenation patterns or the presence or absence of the methyl group at C-7 among others, can attenuate or enhance their biological activities [4,14].

Some of the compounds isolated displayed antibacterial activity against MRSA. Notably, the activity of compound 5, the first in the napiradiomycin D series, was comparable to that of 
other known compounds isolated in this work. In line with previous results, none of the compounds isolated were found to be active against Gram-negative bacteria or fungi. Additionally, our cytotoxicity data illustrate that, for the napyradiomycin B series, the C-3 chlorinated derivatives (compound 2 and 3) exhibit a higher cytotoxic activity compared to the hydroxylated analogous at that stereocenter (compound 6). This cytotoxic is in turn significantly influenced by the absolute stereochemistry of the chlorine group at that position (compound 2 vs. 3 ). On the other hand, there is a clear correlation between rising levels of cytotoxicity when the substitution pattern at C-4a varies between hydroxy group (compound 4), hydrogen (compound 9), or chlorine (compound 13).

\section{Materials and Methods}

\subsection{General Experimental Procedures}

Optical rotations were measured on a Jasco P-2000 polarimeter (JASCO Corporation, Tokyo, Japan). IR spectra were recorded with a JASCO FT/IR-4100 spectrometer (JASCO Corporation) equipped with a PIKE MIRacle ${ }^{\mathrm{TM}}$ single reflection ATR accessory. 1D- and 2D-NMR spectra were recorded on a Bruker Avance III spectrometer (500 and $125 \mathrm{MHz}$ for ${ }^{1} \mathrm{H}$ and ${ }^{13} \mathrm{C}$ NMR, respectively) equipped with a $1.7 \mathrm{~mm}$ TCI MicroCryoProbe ${ }^{\mathrm{TM}}$ (Bruker Biospin, Fällanden, Switzerland). Chemical shifts were reported in ppm using the signals of the residual solvents as internal reference $\left(\delta_{\mathrm{H}} 2.51\right.$ and $\delta_{\mathrm{C}} 39.5 \mathrm{ppm}$ for DMSO- $d_{6}$ ). LC-UV-MS analysis was performed on an Agilent 1100 (Agilent Technologies, Santa Clara, CA, USA) single quadrupole LC-MS system as previously described [24]. ESI-TOF spectra were acquired using a Bruker maXis QTOF (Bruker Daltonik GmbH, Bremen, Germany) mass spectrometer coupled to an Agilent 1200 LC (Agilent Technologies, Waldbronn, Germany). Medium pressure liquid chromatography (MPLC) was performed on semiautomatic flash chromatography (CombiFlash Teledyne ISCO Rf400x) with a precast reversed-phase column. Semi-preparative HPLC separation was performed on Gilson GX-281 322H2 (Gilson Technologies, USA) with a semi-preparative reversed-phase column (Zorbax SB-C18, $250 \times 9.4 \mathrm{~mm}, 5 \mu \mathrm{m}$ ). Preparative HPLC separation was performed on Gilson GX-281 322H2 (Gilson Technologies, USA) with a reversed-phase column (Zorbax SB-C18, $250 \times 21.2 \mathrm{~mm}, 7 \mu \mathrm{m})$. Acetone used for extraction was analytical grade. Solvents employed for isolation were HPLC grade. Molecular models were generated using Chem3D Pro 12.0 (CambridgeSoft, PerkinElmer Informatics, Waltham, MA, USA). The structures were energy-minimized by molecular mechanics with the MM2 force field using as gradient convergence criteria an RMS value of 0.001 . Molecular modelling figures were generated with PyMol (W. L. DeLano, The PyMOL Molecular Graphics System, DeLano Scientific LLC, Palo Alto, CA, USA, 2002). Conformational search was performed for 5 with ConfBuster Web Server, using as input the corresponding sdf files generated with Chem3D Pro 12.0 (CambridgeSoft, PerkinElmer Informatics, Waltham, MA, USA).

\subsection{Taxonomic Identification of the Producing Microorganism}

The taxonomic identification of the strain was described in a previous work [23].

\subsection{Fermentation of the Producing Microorganism}

A $3 \mathrm{~L}$ fermentation of the strain CA-271078 of Streptomyces sp. was generated using the conditions described in reference [23].

\subsection{Extraction and Bioassay Guided Isolation}

The fermentation broth $(3 \mathrm{~L})$ was extracted with acetone $(3 \mathrm{~L})$ under continuous shaking at $220 \mathrm{rpm}$ for $1 \mathrm{~h}$. The mycelium was separated and discarded by centrifugation at $9000 \mathrm{rpm}$ and filtration and the supernatant (ca. $6 \mathrm{~L}$ ) was concentrated to $3 \mathrm{~L}$ under reduced pressure of nitrogen stream. The aqueous crude extract was extracted with EtOAc $(3 \times 0.9 \mathrm{~L})$ to afford a crude extract of $0.178 \mathrm{~g}$. This EtOAc extract was loaded onto a Reversed-Phase C18 (ODS) column $(32 \times 100 \mathrm{~mm})$ that was eluted with a gradient of acetonitrile in water ( $35 \%$ to $100 \% \mathrm{ACN}$ in $50 \mathrm{~min}+100 \% \mathrm{ACN}$ in $10 \mathrm{~min}$, 
$15 \mathrm{~mL} / \mathrm{min}, 18 \mathrm{~mL} /$ fraction) to afford 50 fractions. They were combined into five fractions according to their LC-UV-MS profiles and evaporated to dryness in a centrifugal evaporator: fractions A $(6.6 \mathrm{mg})$, $\mathrm{B}(5.3 \mathrm{mg}), \mathrm{C}(9.0 \mathrm{mg}), \mathrm{D}(12.7 \mathrm{mg})$ and $\mathrm{E}(17.8 \mathrm{mg})$. Fractions containing the compounds of interest from this chromatography were further purified by semipreparative reversed-phase HPLC.

Fraction A $(6.6 \mathrm{mg})$ was chromatographed by semipreparative reversed-phase HPLC (Zorbax SB-C18, $9.4 \times 250 \mathrm{~mm}, 5 \mu \mathrm{m} ; 3.6 \mathrm{~mL} / \mathrm{min}$, UV detection at 210 and $280 \mathrm{~nm}$ ) with an isocratic elution of $33 \% \mathrm{CH}_{3} \mathrm{CN} / 67 \% \mathrm{H}_{2} \mathrm{O}$ with $0.1 \%$ trifluoroacetic acid over $34 \mathrm{~min}$ yielding $\mathbf{1}\left(0.7 \mathrm{mg}, t_{\mathrm{R}} 18 \mathrm{~min}\right)$ and $\mathbf{6}$ (2.1 mg. $\left.t_{\mathrm{R}} 25 \mathrm{~min}\right)$.

Fraction B (5.3 mg) was chromatographed by semipreparative reversed-phase HPLC (Zorbax SB-C18, $9.4 \times 250 \mathrm{~mm}, 5 \mu \mathrm{m} ; 3.6 \mathrm{~mL} / \mathrm{min}$, UV detection at 210 and $280 \mathrm{~nm}$ ) with an isocratic elution of $35 \% \mathrm{CH}_{3} \mathrm{CN} / 65 \% \mathrm{H}_{2} \mathrm{O}$ with $0.1 \%$ trifluoroacetic acid over 34 min yielding 7 (1.1 $\mathrm{mg}, t_{\mathrm{R}} 21.5 \mathrm{~min}$ ).

Fraction C $(9.0 \mathrm{mg}$ ) was subjected to reversed-phase semipreparative HPLC (Zorbax SB-C18, $9.4 \times$ $250 \mathrm{~mm}, 5 \mu \mathrm{m} ; 3.6 \mathrm{~mL} / \mathrm{min}$, UV detection at 210 and $280 \mathrm{~nm}$ ) with and isocratic elution of $\mathrm{CH}_{3} \mathrm{CN} / \mathrm{H}_{2} \mathrm{O}$ $55 / 45$ with $0.1 \%$ trifluoroacetic acid over $34 \mathrm{~min}$, yielding $3\left(0.7 \mathrm{mg}, t_{\mathrm{R}} 15 \mathrm{~min}\right), 4\left(0.5 \mathrm{mg}, t_{\mathrm{R}} 22.5 \mathrm{~min}\right)$, $8\left(0.5 \mathrm{mg}, t_{\mathrm{R}} 20.5 \mathrm{~min}\right)$ and $\mathbf{9}\left(0.5 \mathrm{mg}, t_{\mathrm{R}} 24 \mathrm{~min}\right)$.

Fraction D (12.7 mg) was chromatographed by semipreparative reversed-phase HPLC (Zorbax SB-C18, $9.4 \times 250 \mathrm{~mm}, 5 \mu \mathrm{m} ; 3.6 \mathrm{~mL} / \mathrm{min}$, UV detection at 210 and $280 \mathrm{~nm}$ ) with a linear gradient of $\mathrm{CH}_{3} \mathrm{CN} / \mathrm{H}_{2} \mathrm{O}$ with $0.1 \%$ trifluoroacetic acid, from 55 to $65 \% \mathrm{CH}_{3} \mathrm{CN}$ over $34 \mathrm{~min}$, yielding 2 (1.3 mg, $\left.t_{\mathrm{R}} 23.5 \mathrm{~min}\right), \mathbf{1 0}\left(0.8 \mathrm{mg}, t_{\mathrm{R}} 25.2 \mathrm{~min}\right), \mathbf{1 1}\left(0.9 \mathrm{mg}, t_{\mathrm{R}} 27 \mathrm{~min}\right), \mathbf{1 2}\left(1.3 \mathrm{mg}, t_{\mathrm{R}} 28.5 \mathrm{~min}\right)$ and $\mathbf{1 3}(0.9 \mathrm{mg}$, $\left.t_{\mathrm{R}} 31 \mathrm{~min}\right)$.

Fraction E (12.7 mg) was subjected to reversed-phase semipreparative HPLC (Zorbax SB-C18, $9.4 \times 250 \mathrm{~mm}, 5 \mu \mathrm{m} ; 3.6 \mathrm{~mL} / \mathrm{min}$, UV detection at 210 and $280 \mathrm{~nm}$ ) with a linear gradient $\mathrm{Cf}_{3} \mathrm{CN} /$ $\mathrm{H}_{2} \mathrm{O}$ with $0.1 \%$ trifluoroacetic acid, from 65 to $70 \% \mathrm{CH}_{3} \mathrm{CN}$ over $34 \mathrm{~min}$, yielding $5\left(1.0 \mathrm{mg}\right.$, $\left.t_{\mathrm{R}} 21 \mathrm{~min}\right)$, $14\left(1.0 \mathrm{mg}, t_{\mathrm{R}} 27.5 \mathrm{~min}\right)$ and $\mathbf{1 5}\left(1.0 \mathrm{mg}, t_{\mathrm{R}} 32.5 \mathrm{~min}\right)$.

\subsection{Characterization Data}

Napyradiomycin A3 (1): $[\alpha]_{25}^{\mathrm{D}}+4.0$ (c 0.38, MeOH); IR (ATR) $\mathrm{cm}^{-1}: 3379,2977,1702,1673,1619,1267$, 1186, 1136, 1024, 837, 720; (+)-ESI-TOFMS $m / z 465.1877[\mathrm{M}+\mathrm{Na}]^{+}$(calcd. for $\mathrm{C}_{25} \mathrm{H}_{30} \mathrm{NaO}_{7}{ }^{+}, 465.1884$ ), $460.2330\left[\mathrm{M}+\mathrm{NH}_{4}\right]^{+}$(calcd. for $\mathrm{C}_{25} \mathrm{H}_{34} \mathrm{NO}_{7}{ }^{+}, 460.2330$ ), 443,2060 [M + H] $]^{+}$(calcd. for $\mathrm{C}_{25} \mathrm{H}_{31} \mathrm{O}_{7}{ }^{+}$, 443.2064), $425.1958\left[\mathrm{M}+\mathrm{H}-\mathrm{H}_{2} \mathrm{O}\right]^{+}$(calcd. for $\left.\mathrm{C}_{25} \mathrm{H}_{29} \mathrm{O}_{6}{ }^{+}, 425.1960\right) ;{ }^{1} \mathrm{H}$ and ${ }^{13} \mathrm{C}$ NMR data see Tables 1 and 2.

Napyradiomycin B7a (2): $[\alpha]_{25}^{\mathrm{D}}-41.0$ (c 0.4, MeOH); IR (ATR) cm ${ }^{-1}$ : 3374, 2930, 1680, 1615, 1377, 1260, $1202,1137,1025,798,722$; (+)-ESI-TOFMS $m / z$ 1010.3184 [2M + $\left.\mathrm{NH}_{4}\right]^{+}$(calcd. for $\mathrm{C}_{50} \mathrm{H}_{64}{ }^{35} \mathrm{Cl}_{4} \mathrm{NO}_{12}{ }^{+}$, 1010.3177), 514.1753 [M + NH 4$]^{+}$(calcd. for $\left.\mathrm{C}_{25} \mathrm{H}_{34}{ }^{35} \mathrm{Cl}_{2} \mathrm{NO}_{6}{ }^{+}, 514.1758\right), 479.1389\left[\mathrm{M}+\mathrm{H}-\mathrm{H}_{2} \mathrm{O}\right]^{+}$ (calcd. for $\mathrm{C}_{25} \mathrm{H}_{29}{ }^{35} \mathrm{Cl}_{2} \mathrm{O}_{5}{ }^{+}, 479.1387$ ), $461.1284\left[\mathrm{M}+\mathrm{H}-2 \mathrm{H}_{2} \mathrm{O}\right]^{+}$(calcd. for $\mathrm{C}_{25} \mathrm{H}_{27}{ }^{35} \mathrm{Cl}_{2} \mathrm{O}_{4}{ }^{+}, 461.1281$ ); ${ }^{1} \mathrm{H}$ and ${ }^{13} \mathrm{C}$ NMR data see Tables 1 and 2.

Napyradiomycin B7b (3): $[\alpha]_{25}^{\mathrm{D}}+32.0$ (c 0.13, MeOH); IR (ATR) $\mathrm{cm}^{-1}: 3368,2980,1680,1618,1455,1378$, 1268, 1204, 1137, 803; (+)-ESI-TOFMS $\mathrm{m} / \mathrm{z} 1010.3191\left[2 \mathrm{M}+\mathrm{NH}_{4}\right]^{+}$(calcd. for $\mathrm{C}_{50} \mathrm{H}_{64}{ }^{35} \mathrm{Cl}_{4} \mathrm{NO}_{12}{ }^{+}$, 1010.3177), 514.1752 [M + NH 4$]^{+}$(calcd. for $\left.\mathrm{C}_{25} \mathrm{H}_{34}{ }^{35} \mathrm{Cl}_{2} \mathrm{NO}_{6}{ }^{+}, 514.1758\right), 479.1394\left[\mathrm{M}+\mathrm{H}-\mathrm{H}_{2} \mathrm{O}\right]^{+}$ (calcd. for $\mathrm{C}_{25} \mathrm{H}_{29}{ }^{35} \mathrm{Cl}_{2} \mathrm{O}_{5}{ }^{+}, 479.1387$ ), $461.1294\left[\mathrm{M}+\mathrm{H}-2 \mathrm{H}_{2} \mathrm{O}\right]^{+}$(calcd. for $\mathrm{C}_{25} \mathrm{H}_{27}{ }^{35} \mathrm{Cl}_{2} \mathrm{O}_{4}{ }^{+}$, 461.1281), $443.1629\left[\mathrm{M}+\mathrm{H}-3 \mathrm{H}_{2} \mathrm{O}\right]^{+}$(calcd. for $\left.\mathrm{C}_{25} \mathrm{H}_{25}{ }^{35} \mathrm{Cl}_{2} \mathrm{O}_{3}{ }^{+}, 443.1175\right) ;{ }^{1} \mathrm{H}$ and ${ }^{13} \mathrm{C}$ NMR data see Tables 1 and 2.

Napyradiomycin SC (4): $[\alpha]_{25}^{\mathrm{D}}-43.0$ (c 0.4, MeOH); IR (ATR) $\mathrm{cm}^{-1}: 3340,2976,1703,1632,1615,1464,1372$, 1264, 1224, 1183, 1082, 1024; (+)-ESI-TOFMS $\mathrm{m} / z 497.1499\left[\mathrm{M}+\mathrm{H}-\mathrm{H}_{2} \mathrm{O}\right]^{+}$(calcd. for $\mathrm{C}_{25} \mathrm{H}_{31}{ }^{35} \mathrm{Cl}_{2} \mathrm{O}_{6}{ }^{+}$, 497.1492), $479.1389\left[\mathrm{M}+\mathrm{H}-2 \mathrm{H}_{2} \mathrm{O}\right]^{+}$(calcd. for $\mathrm{C}_{25} \mathrm{H}_{28}{ }^{35} \mathrm{Cl}_{2} \mathrm{O}_{5}{ }^{+}, 479.1387$ ); ${ }^{1} \mathrm{H}$ and ${ }^{13} \mathrm{C}$ NMR data see Tables 1 and 2. 
Napyradiomycin D1 (5): $[\alpha]_{25}^{\mathrm{D}}+14.6$ (c 0.13, MeOH); IR (ATR) $\mathrm{cm}^{-1}: 3358,2978,2948,1671,1608$, 1458, 1371, 1298, 1185, 1136, 1079, 1028, 802; (+)-ESI-TOFMS m/z 479.1386 [M + H] ${ }^{+}$(calcd. for $\left.\mathrm{C}_{25} \mathrm{H}_{29}{ }^{35} \mathrm{Cl}_{2} \mathrm{O}_{5}{ }^{+}, 479.1387\right) ;{ }^{1} \mathrm{H}$ and ${ }^{13} \mathrm{C}$ NMR data see Tables 1 and 2.

\subsection{Antibacterial and Antifungal Assays Cytotoxic Activities}

Compounds 1-15 were tested in antimicrobial assays against the growth of Gram-negative (E. coli ATCC 25922 and A. baumannii MB5973) and Gram-positive bacteria (M. tuberculosis H37Ra and methicillin-resistant S. aureus (MRSA) MB5393), and fungi (A. fumigatus ATCC46645) and in a cytotoxicity assay against the human liver adenocarcinoma cell line (HepG2) following previously described methodologies [36-38]. Briefly, each compound was serially diluted in DMSO with a dilution factor of 2 to provide 10 concentrations starting at $96 \mu \mathrm{g} / \mathrm{mL}$ for all the antimicrobial assays except for compounds 3 and 8 which started at $64 \mu \mathrm{g} / \mathrm{mL}$. For the adenocarcinoma cell line each compound was serially diluted in DMSO with a dilution factor of 2 to provide 10 concentrations starting at $150 \mu \mathrm{g} / \mathrm{mL}$ (compounds 2, 4, 6, 7, and 9-15), $100 \mu \mathrm{g} / \mathrm{mL}$ (compounds 3 and 8) or $30.0 \mu \mathrm{g} / \mathrm{mL}$ (compounds 1 and 5). The MIC was defined as the lowest concentration of compound that inhibited $\geq 95 \%$ of the growth of a microorganism after overnight incubation. The Genedata Screener software (Genedata, Inc., Basel, Switzerland) was used to process and analyze the data and also to calculate the RZ' factor, which predicts the robustness of an assay [39]. In all experiments performed in this work the RZ' factor obtained was between 0.87 and 0.98 .

\section{Conclusions}

In this work, we report the isolation and structural characterization of four new napyradiomycins $(1-3,5)$ and the known napyradiomycin SC $(4)$, whose structural details had not been previously described. Additionally, another ten known napyradiomycins or related compounds (6-15) were also isolated from the same culture broth of the marine-derived Streptomyces sp. CA-271078 from MEDINA's microbial collection. The antibacterial, antifungal and cytotoxic properties of all the compounds isolated were tested. Napyradiomycins B2 (14), B4 (13), and B5 (15) and the new napyradiomycin D1 (5) were the most active compounds, exhibiting similar antibacterial activities against MRSA and M. tuberculosis H37Ra, as well as comparable cytotoxic activities against the HepG2 tumoral cell line. On the contrary, none of the compound tested showed significant activity against E. coli, A. baumannii, or A. fumigatus.

The four new compounds isolated displayed remarkable structural features. Thus, compound $\mathbf{1}$ is the first member of napyradiomycins in the A series bearing a hydroxy group rather than a chlorine atom at C-3. The isolation of the new B-type napyradiomycin 3 represents to our knowledge the first example reported with a different relative configuration at the $\mathrm{C}-3$ chlorinated position in napyradiomycins and raises biosynthetic and mechanistic questions to be considered. Compound 5 harbors in its structure an unprecedented 16-membered macrocyclic ether ring between the naphthoquinone moiety and the monoterpenoid chain, thus inaugurating a new class of napyradiomycins, the D series.

The results reported here highlight the wide range of structural possibilities for napyradiomycin metabolites. The further whole genome sequencing of the producer strain CA-271078 and the analysis of the corresponding napyradiomycins gene cluster could bring new data about the biosynthesis of these fascinating natural products.

Supplementary Materials: The following are available online at http://www.mdpi.com/1660-3397/18/1/22/s1, Figures S1-S7, S9-S16, S18-S25, S27-S33, and S35-S41: UV, ESI-TOF, and 1D and 2D NMR spectra of compound 1-5. Figures S8, S17, S26, and S34: Energy minimized molecular model of compound 1-4. Figure S42: Overlay of different conformers for compound 5. Figure S43: Napyradiomycin metabolites isolated from CA-271078 (1-15).

Author Contributions: D.C.-M. performed the extraction of the culture broths and the isolation of the compounds. D.O.-C. carried out the fermentation and the taxonomic identification of the microbial strain. C.D., M.d.1.C. performed the antibacterial and antifungal assays. B.C. performed the cytotoxicity assays. D.C.-M. and F.J.O.-L. analyzed the spectroscopic data and elucidated the structure of the new molecules. J.M. performed the LC/MS analyses and analyzed and interpreted the ESI-TOF spectra. F.R., O.G., and F.V. conceived the research and 
supervised the work. F.J.O.-L. and D.C.-M. wrote the original draft of paper, which was revised by F.R. and approved by all the authors. All authors have read and agreed to the published version of the manuscript.

Funding: This work has been partially funded by the European Union's Seventh Framework Programme for research, technological development, and demonstration under grant agreement no 312184 (PharmaSea). The polarimeter, HPLC, IR, and NMR equipment used in this work were acquired via two grants for scientific and technological infrastructures from the Ministerio de Ciencia e Innovación [Grants No. PCT-010000-2010-4 (NMR) and INP-2011-0016-PCT-010000-ACT6 (Polarimeter, HPLC and IR)]. D.C.-M acknowledges the Ministerio de Economía y Competitividad the funding of a contract under the Youth Employment Initiative of the European Social Fund (PEJ-2014-A-29071).

Acknowledgments: The authors acknowledge the assistance of M. Estévez in the fermentation of the strain, and P. Mena, M. A. Melguizo, P. Sánchez, and T. A. Andrew Mackenzie for technical assistance with antimicrobial and cytotoxicity assays. The published results are part of the doctoral thesis of Daniel Carretero-Molina.

Conflicts of Interest: The authors declare no conflict of interest.

\section{References}

1. Shiomi, K.; Nakamura, H.; Iinuma, H.; Naganawa, H.; Isshiki, K.; Takeuchi, T.; Umezawa, H.; Iitaka, Y. Structures of new antibiotics napyradiomycins. J. Antibiot. 1986, 39, 494-501. [CrossRef]

2. Fukuda, D.S.; Mynderse, J.S.; Baker, P.J.; Berry, D.M.; Boeck, L.D.; Yao, R.C.; Mertz, F.P.; Nakatsukasa, W.M.; Mabe, J.; Ott, J.; et al. A80915, a new antibiotic complex produced by Streptomyces aculeolatus. Discovery, taxonomy, fermentation, isolation, characterization, and antibacterial evaluation. J. Antibiot. 1990, 43, 623-633. [CrossRef]

3. Soria-Mercado, I.E.; Prieto-Davo, A.; Jensen, P.R.; Fenical, W. Antibiotic terpenoid chloro-dihydroquinones from a new marine actinomycete. J. Nat. Prod. 2005, 68, 904-910. [CrossRef] [PubMed]

4. Wu, Z.; Li, S.; Li, J.; Chen, Y.; Saurav, K.; Zhang, Q.; Zhang, H.; Zhang, W.; Zhang, W.; Zhang, S.; et al. Antibacterial and cytotoxic new napyradiomycins from the marine-derived Streptomyces sp. SCSIO 10428. Mar. Drugs 2013, 11, 2113-2125. [CrossRef] [PubMed]

5. Haste, N.M.; Farnaes, L.; Perera, V.R.; Fenical, W.; Nizet, V.; Hensler, M.E. Bactericidal kinetics of marine-derived napyradiomycins against contemporary methicillin-resistant Staphylococcus aureus. Mar. Drugs 2011, 9, 680-689. [CrossRef] [PubMed]

6. Motohashi, K.; Sue, M.; Furihata, K.; Ito, S.; Seto, H. Terpenoids produced by actinomycetes: Napyradiomycins from Streptomyces antimycoticus NT17. J. Nat. Prod. 2008, 71, 595-601. [CrossRef]

7. Henkel, T.; Zeeck, A. Secondary metabolites by chemical screening. 15. Structure and absolute configuration of naphthomevalin, a new dihydro-naphthoquinone antibiotic from Streptomyces sp. J. Antibiot. 1991, 44, 665-669. [CrossRef]

8. Shiomi, K.; Nakamura, H.; Iinuma, H.; Naganawa, H.; Takeuchi, T.; Umezawa, H.; Iitaka, Y. New antibiotic napyradiomycins A2 and B4 and stereochemistry of napyradiomycins. J. Antibiot. 1987, 40, 1213-1219. [CrossRef]

9. Soria-Mercado, I.E.; Jensen, P.R.; Fenical, W.; Kassel, S.; Golen, J. 3,4a-Dichloro-10a-(3-chloro-6-hydroxy-2,2,6trimethylcyclohexylmethyl)-6,8-dihydroxy-2,2,7-trimethyl-3,4,4a,10a-tetrahydro-2H-benzo[g]chromene-5,10dione. Acta Crystallogr. Sect. E 2004, 60, o1627-o1629. [CrossRef]

10. Gomi, S.; Ohuchi, S.; Sasaki, T.; Itoh, J.; Sezaki, M. Studies on new antibiotics SF2415. 2. The structural elucidation. J. Antibiot. 1987, 40,740-749. [CrossRef]

11. Umezawa, K.; Masuoka, S.; Ohse, T.; Naganawa, H.; Kondo, S.; Ikeda, Y.; Kinoshita, N.; Hamada, M.; Sawa, T.; Takeuchi, T. Isolation from Streptomyces of a novel naphthoquinone compound, naphthablin, that inhibits Abl oncogene functions. J. Antibiot. 1995, 48, 604-607. [CrossRef] [PubMed]

12. Cho, J.Y.; Kwon, H.C.; Williams, P.G.; Jensen, P.R.; Fenical, W. Azamerone, a terpenoid phthalazinone from a marine-derived bacterium related to the genus Streptomyces (actinomycetales). Org. Lett. 2006, 8, 2471-2474. [CrossRef] [PubMed]

13. Motohashi, K.; Irie, K.; Toda, T.; Matsuo, Y.; Kasai, H.; Sue, M.; Furihata, K.; Seto, H. Studies on terpenoids produced by actinomycetes. 5-Dimethylallylindole-3-carboxylic acid and A80915G-8"-acid produced by marine-derived Streptomyces sp. MS239. J. Antibiot. 2008, 61, 75-80. [CrossRef] [PubMed] 
14. Farnaes, L.; Coufal, N.G.; Kauffman, C.A.; Rheingold, A.L.; DiPasquale, A.G.; Jensen, P.R.; Fenical, W. Napyradiomycin derivatives, produced by a marine-derived actinomycete, illustrate cytotoxicity by induction of apoptosis. J. Nat. Prod. 2014, 77, 15-21. [CrossRef]

15. Farnaes, L.; La Clair, J.J.; Fenical, W. Napyradiomycins CNQ525.510B and A80915C target the Hsp90 paralogue Grp94. Org. Biomol. Chem. 2014, 12, 418-423. [CrossRef]

16. Hori, Y.; Abe, Y.; Shigematsu, N.; Goto, T.; Okuhara, M.; Kohsaka, M. Napyradiomycin A and B1: Non-steroidal estrogen-receptor antagonists produced by a Streptomyces. J. Antibiot. 1993, 46, 1890-1893. [CrossRef]

17. Dantzig, A.H.; Minor, P.L.; Garrigus, J.L.; Fukuda, D.S.; Mynderse, J.S. Studies on the mechanism of action of A80915A, a semi-naphthoquinone natural product, as an inhibitor of gastric (H+-K+)-ATPase. Biochem. Pharmacol. 1991, 42, 2019-2026. [CrossRef]

18. Shiomi, K.; Iinuma, H.; Hamada, M.; Naganawa, H.; Manabe, M.; Matsuki, C.; Takeuchi, T.; Umezawa, H. Novel antibiotics napyradiomycins. Production, isolation, physicochemical properties and biological activity. J. Antibiot. 1986, 39, 487-493. [CrossRef]

19. Prestinaci, F.; Pezzotti, P.; Pantosti, A. Antimicrobial resistance: A global multifaceted phenomenon. Pathog. Glob. Health 2015, 109, 309-318. [CrossRef]

20. Carroll, A.R.; Copp, B.R.; Davis, A.R.; Davis, R.A.; Keyzersd, R.A.; Prinsepe, M.R. Marine natural products. Nat. Prod. Rep. 2019, 36, 122-173. [CrossRef]

21. Hassan, S.S.; Shaikh, A.L. Marine actinobacteria as a drug treasure house. Biomed. Pharmacother. 2017, 87, 46-57. [CrossRef] [PubMed]

22. Lacret, R.; Oves-Costales, D.; Gómez, C.; Díaz, C.; de la Cruz, M.; Pérez-Victoria, I.; Vicente, F.; Genilloud, O.; Reyes, F. New ikarugamycin derivatives with antifungal and antibacterial properties from Streptomyces zhaozhouensis. Mar. Drugs 2015, 13, 128-140. [CrossRef] [PubMed]

23. Lacret, R.; Pérez-Victoria, I.; Oves-Costales, D.; de la Cruz, M.; Domingo, E.; Martín, J.; Díaz, C.; Vicente, F.; Genilloud, O.; Reyes, F. MDN-0170, a new napyradiomycin from Streptomyces sp. strain CA-271078. Mar. Drugs 2016, 14, 188. [CrossRef] [PubMed]

24. Pérez-Victoria, I.; Martín, J.; Reyes, F. Combined LC/UV/MS and NMR strategies for the dereplication of marine natural products. Planta Med. 2016, 82, 857-871. [CrossRef] [PubMed]

25. Dictionary of Natural Products (DNP 2019). Chapman \& Hall/CRC. Available online: http://dnp.chemnetbase. com/faces/chemical/ChemicalSearch.xhtml (accessed on 26 November 2019).

26. Cheng, Y.-B.; Jensen, P.R.; Fenical, W. Cytotoxic and antimicrobial napyradiomycins from two marine-derived Streptomyces strains. Eur. J. Org. Chem. 2013, 18, 3751-3757. [CrossRef]

27. Kamimura, D.; Yamada, K.; Tsuji, T. Agent for Inhibiting Production of Venous Cell-Adhering Molecule-1 and Napyradiomycin SC. Japanese Patent 09110689, 28 April 1997.

28. Winter, J.M.; Moffitt, M.C.; Zazopoulos, E.; McAlpine, J.B.; Dorrestein, P.C.; Moore, B.S. Molecular basis for chloronium-mediated meroterpene cyclization: Cloning, sequencing, and heterologous expression of the napyradiomycin biosynthetic gene cluster. J. Biol. Chem. 2007, 282, 16362-16368. [CrossRef]

29. McKinnie, S.M.K.; Miles, Z.D.; Jordan, P.A.; Awakawa, T.; Pepper, H.P.; Murray, L.A.M.; George, J.H.; Moore, B.S. Total enzyme syntheses of napyradiomycins A1 and B1. J. Am. Chem. Soc. 2018, 140, 17840-17845. [CrossRef]

30. Barbeau, X.; Vincent, A.T.; Lagüe, P. ConfBuster: Open-source tools for macrocycle conformational search and analysis. J. Open Res. Softw. 2018, 6, 1. [CrossRef]

31. Bernhardt, P.; Okino, T.; Winter, J.M.; Miyanaga, A.; Moore, B.S. A stereoselective vanadium-dependent chloroperoxidase in bacterial antibiotic biosynthesis. J. Am. Chem. Soc. 2011, 133, 4268-4270. [CrossRef]

32. Wever, R.; Krenn, B.E.; Renirie, R. Marine vanadium-dependent haloperoxidases, their isolation, characterization, and application. Methods Enzymol. 2018, 605, 141-201. [CrossRef]

33. Diethelm, S.; Teufel, R.; Kaysser, L.; Moore, B.S. A multitasking vanadium-dependent chloroperoxidase as an inspiration for the chemical synthesis of the merochlorins. Angew. Chem. Int. Ed. 2014, 53, 11023-11026. [CrossRef] [PubMed]

34. McKinnie, S.M.K.; Miles, Z.D.; Moore, B.S. Characterization and biochemical assays of Streptomyces vanadium-dependent chloroperoxidases. Methods Enzymol. 2018, 604, 405-424. [CrossRef] [PubMed] 
35. Kaysser, L.; Bernhardt, P.; Nam, S.J.; Loesgen, S.; Ruby, J.G.; Skewes-Cox, P.; Jensen, P.R.; Fenical, W.; Moore, B.S. Merochlorins A-D, cyclic meroterpenoid antibiotics biosynthesized in divergent pathways with vanadium-dependent chloroperoxidases. J. Am. Chem. Soc. 2012, 134, 11988-119991. [CrossRef] [PubMed]

36. Martín, J.; da S Sousa, T.; Crespo, G.; Palomo, S.; González, I.; Tormo, J.R.; de la Cruz, M.; Anderson, M.; Hill, R.T.; Vicente, F.; et al. Kocurin, the true structure of PM181104, an anti-methicillin-resistant Staphylococcus aureus (MRSA) thiazolyl peptide from the marine-derived bacterium Kocuria palustris. Mar. Drugs 2013, 11, 387-398. [CrossRef]

37. Monteiro, M.C.; de la Cruz, M.; Cantizani, J.; Moreno, C.; Tormo, J.R.; Mellado, E.; De Lucas, J.R.; Asensio, F.; Valiante, V.; Brakhage, A.A.; et al. A new approach to drug discovery: High-throughput screening of microbial natural extracts against Aspergillus fumigatus using resazurin. J. Biomol. Screen. 2012, 17, 542-549. [CrossRef]

38. Zhang, L.; Ravipati, A.S.; Koyyalamudi, S.R.; Jeong, S.C.; Reddy, N.; Bartlett, J.; Smith, P.T.; de la Cruz, M.; Monteiro, M.C.; Melguizo, A.; et al. Anti-fungal and anti-bacterial activities of ethanol extracts of selected traditional chinese medicinal herbs. Asian Pac. J. Trop. Med. 2013, 6, 673-681. [CrossRef]

39. Zhang, J.H.; Chung, T.D.; Oldenburg, K.R. A simple statistical parameter for use in evaluation andvalidation of high throughput screening assays. J. Biomol. Screen. 1999, 4, 67-73. [CrossRef]

(C) 2019 by the authors. Licensee MDPI, Basel, Switzerland. This article is an open access article distributed under the terms and conditions of the Creative Commons Attribution (CC BY) license (http://creativecommons.org/licenses/by/4.0/). 